\title{
Review
}

\section{Flexible Sensors Based on Conductive Polymers}

\author{
Ileana-Alexandra Pavel $* \mathbb{D}$, Sophie Lakard and Boris Lakard
}

check for

updates

Citation: Pavel, I.-A.; Lakard, S.; Lakard, B. Flexible Sensors Based on Conductive Polymers. Chemosensors 2022, 10, 97. https://doi.org/ 10.3390/chemosensors10030097

Academic Editors: Miriam

Trigo-López and Aránzazu Mendía

Received: 17 January 2022

Accepted: 24 February 2022

Published: 1 March 2022

Publisher's Note: MDPI stays neutral with regard to jurisdictional claims in published maps and institutional affiliations.

Copyright: (c) 2022 by the authors Licensee MDPI, Basel, Switzerland. This article is an open access article distributed under the terms and conditions of the Creative Commons Attribution (CC BY) license (https:// creativecommons.org/licenses/by/ $4.0 /)$.
Institut UTINAM, UMR CNRS 6213, University of Bourgogne Franche-Comté, 16 Route de Gray, 25030 Besançon, France; sophie.lakard@univ-fcomte.fr (S.L.); boris.lakard@univ-fcomte.fr (B.L.)

* Correspondence: ileana-alexandra.pavel-licsandru@univ-fcomte.fr; Tel.: +33-3-8166-6711

\begin{abstract}
Conductive polymers have attracted wide attention since their discovery due to their unique properties such as good electrical conductivity, thermal and chemical stability, and low cost. With different possibilities of preparation and deposition on surfaces, they present unique and tunable structures. Because of the ease of incorporating different elements to form composite materials, conductive polymers have been widely used in a plethora of applications. Their inherent mechanical tolerance limit makes them ideal for flexible devices, such as electrodes for batteries, artificial muscles, organic electronics, and sensors. As the demand for the next generation of (wearable) personal and flexible sensing devices is increasing, this review aims to discuss and summarize the recent manufacturing advances made on flexible electrochemical sensors.
\end{abstract}

Keywords: conductive polymers; flexible sensors; polymer composite; smart sensors

\section{Introduction}

Flexible conductive materials have attracted extensive research due to their potential in applications such as health-monitoring and implantable medical devices, robotic smart skin, wearable energy storage devices, human-machines interfaces, and wearable and flexible electronic systems. Conductive polymers (CP) have gained rapid development since their discovery. Their conductivity can be tuned by doping, by chemically changing their structure or by combining them with different additives, i.e., metals, semiconductors, acids or even surfactants [1]. Flexible sensors, an important part of new and modern electronics, have also attracted a lot of attention [2]. Polymers are used in the construction of flexible devices, as they have high shock resistance as well as low weight, flexibility, and softness, tailorable structure and low cost. The most popular conductive polymers used in flexible sensors [3] are polypyrrole (PPy), polyaniline (PANI), polythiophene [4], and poly(3,4-ethylenedioxythiophene) polystyrene sulfonate (PEDOT:PSS) [5] (Figure 1).
A<smiles>Cc1ccc(-c2ccc(C(C)(C)C)[nH]2)[nH]1</smiles>

B

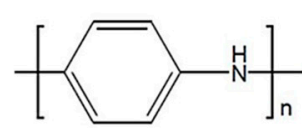

D<smiles>CC(C)(C)c1ccc(C(C)(C)C)s1</smiles>

C<smiles>[X]C(C)(C)c1sc(C(C)(C)C)c2c1OCCO2</smiles><smiles>CC(CC(C)(C)C)C(C)(C)C</smiles><smiles>CS(=O)(=O)c1ccccc1</smiles>

Figure 1. (A). Poplypyrrole, (B). Polyaniline, (C). Poly(3,4-ethylenedioxythiophene) polystyrene sulfonate, (D). Polythiophene.

The main ways to produce flexible conductive polymer-based sensors are: 
(i) in the case of a flexible support, as with fiber materials (polyester or cotton fibers), flexible polymers polyimide (PI), polydimethylsiloxane (PDMS), polyethylene terephthalate (PET), Kapton [6] or even paper [7] can be produced by:

- the polymerizing of a thin layer of $\mathrm{CP}$ directly on the surface by electropolymerization, vapor phase polymerization or in situ polymerization;

- coating/dyeing or printing [8-11] a solution or a suspension containing the polymer;

- wet [12,13], melt or electro [14] spinning of the CP;

(ii) by modifying the structure of the conductive polymer. CPs have a highly $\pi$-conjugated structure that leads to rigidity and high stiffness. By changing the synthesis method or by adding counterions, [15] soft polymers, [16] ionic liquids, [17] surfactants, [18,19] or polyvinyl alcohol [20], the CPs will increase their flexibility and stretchability.

(iii) by growing $\mathrm{CP}$ structures, by electrochemical or chemical oxidative polymerization in a flexible matrix, as gels [21,22] or elastomers.

Flexible sensors have been attracting great attention due to their potential to be used as wearable chemical sensors $[23,24]$ in the fields of sports $[25,26]$ and health [27], medicine and occupational safety [28]. Hazard identification by monitoring in real-time the body status and the surrounding environment, allows for fast response in order to take countermeasure against potential damage [29-31].

An important aspect of the sensors when used for health and medical applications is biocompatibility [32,33]. In medicine, flexible sensors can be used for blood pressure measurements, [34] electrocardiographic (ECG) monitoring, [35] electromyography (sEMG) [36] and non-invasive exhaled breath analysis [37,38]. In environmental applications, they are used for pressure and humidity measurements [39], gas sensing [40-44], or temperature measurements [45].

The main goal of this review is an overview of the preparation methods of conductive polymer-based flexible sensors. We focused our study by relating to different types of flexible sensors that incorporate conductive polymers. Although all types of flexible sensors are studied, $\mathrm{CP}$ are most of the time studied as a component for piezoresistive and gas sensors. In this paper piezoresistive, gas, $\mathrm{pH}$ and ions, biosensors, temperature and humidity sensors, and actuators are discussed in the order of most commonly employed to least commonly employed type. As the most studied flexible devices are the piezoresistive ones, the subchapter is divided according to the $\mathrm{CP}$.

\section{Piezoresistive Sensors}

Piezoresistive sensors transduce mechanical strains such as pressure, force (friction, Coriolis, etc.), mass, displacement, deformation, torque, cracks, creep, fatigue, flow, level, height, or acceleration into an electrical resistance change. There are two main strategies to obtain a flexible piezoresistive sensor. Usually, a conductive filler such as metals or carbon nanotubes (CNTs) are incorporated in an elastic material [46,47]. Carbon-based materials are generally used as they are highly conductive, but they can be expensive. Polymers like polyurethane (PU) or poly(dimethylsiloxane) are used due to their excellent optical and mechanical properties such as elasticity, low density, or transparency. The second strategy is the use of conductive polymers as the sensor [48] but also as a filler [49]. Significant advances have been made in improving the flexibility of conjugated polymers by changing their chemistry or the strategies to design the material [50].

\subsection{Polypyrrole}

Polypyrrole was used as a coating for polyurethane foam [51] to prepare wearable pressure sensors. The conductive polymer, prepared by chemical polymerization, coated the foam, and formed a soft, compressible, and versatile material, with a large surface area, excellent fluid absorbance properties and robustness under repeated compression and expansion.

Another method to form a polypyrrole film at the surface of an elastic and stretchable material is the vapor phase polymerization (VPP) technique. A layer of $\mathrm{FeCl}_{3}$ oxidant was 
deposited onto natural rubber strips, then exposed to pyrrole monomers, providing a good adhesion between the two components of the strain sensing element. Various deposition parameters were employed to obtain a sensor able to detect large mechanical strain [52].

Different strategies have been employed to increase the flexible electrode's characteristics. To increase the elasticity of polypyrrole films, Pan et al. introduced hollow-sphere microstructures during a multistep synthesis forming an ultra-sensitive resistive pressure sensor [53]. Hemisphere structures were fabricated by interlocking two elastic patterned nanofibrous membranes to increase the sensibility. The 3D elastic and porous protrusions structure was formed by Poly(vinyl alcohol-co-ethylene) (PVAco-PE nanofibers) coated PPy and elastic polyolefin elastomer (POE) nanofibers. The interconnecting scaffold offered the sensor a tunable effective elastic modulus, capable of capturing varied strains and stresses. Combined with an LED system, the patterned nanofibrous sensors can be used in visual detection applications [54]. The sensibility of a sensor can also be adapted by modifying one of the component's structures. For example, a two component pressure sensor, composed of an Au micropillar array and a deformable PPy film chemically deposited on a PDMS substrate, showed tunable sensibility by varying the gold pillar diameter [55].

PPy can be used not only as a film but also in the form of particles. Chen at al. [56] uniformly dispersed PPy particles in an elastic supramolecular polymer matrix, cross-linked by multiple hydrogen-bonding 2-ureido-4[1H]-pyrimidinone (UPy) groups. This network promoted not only the transport of electrons but also provided mechanical reinforcement to the hybrid system, exhibited strong adhesiveness to a broad range of organic and inorganic substrates, and was used as a strain sensor for the detection of both subtle and large human motions (pulse beating and finger movement). Another way that pyrrole is integrated in sensors is by incorporating it in hydrogels. Hydrogels are soft material, with biological tissue like structure, high flexibility and good viscoelasticity. A multifunctional autonomicintrinsic conductive self-healing hydrogel was reported by Darabi et al. [57]. The physically and chemically crosslinked hydrogel network was prepared in a twostep synthesis. First, on a double-bond decorated chitosan, PPy was grafted (DCh-PPy). Then acrylic acid monomers were chemically polymerized in the presence of DCh-PPy and ferric irons to form a poly(acrylic acid)(PAA) double network hydrogel. The reversible ionic interactions between carboxylic groups of PAA and -NH groups of PPy and ferric ions led to an autonomous and fast self-healing of the material. This sensor-based hydrogel showed a good sensing performance (respiratory, pulse, and muscle motions detection), 3D printability, and stretchability. Zhang et al. [58] proposed a multifunctional hemicellulose-polypyrrole composite hydrogel that showed good mechanical property, water retention, anti-freezing performance, and thermo-plasticity. Hemicellulose-conductive polymer composite (H/PPy) was formed in water in the presence of phytic acid (to induce the Py polymerization due to the multiple hydrogen bonds formed between the rich oxygen-containing groups of the acid and the monomer) and $\mathrm{FeCl}_{3}$ (as a dopant, to increase the electrical conductivity). The PVA/BGL-H/PPy hydrogel was then prepared by mixing together the H/PPy suspension, PVA, glycerol, and borax, followed by freezing treatment and thawing. The formed sensors were able to detect throat deforming during speaking and drinking, as well as body motions such as finger and wrist bending.

Gan et al. [59] prepared hydrophobic PPy nanorods, uniformly distributed and integrated with a hydrophilic polymer phase (Figure 2). The highly interconnected conductive path in the hydrogel led to the detection of wrist motion, sensing the releasing and the clenching of the hand. In order to obtain this conductive hydrogel-based sensor, with good biocompatibility, superior mechanical properties, and excellent conductivity, a polyacrylamide/chitosan framework was used as a molecular template. After its synthesis by UV photopolymerization, hydrophobic and conductive pyrrole monomers were added, and polymerized in situ by $\mathrm{FeCl}_{3}$. 


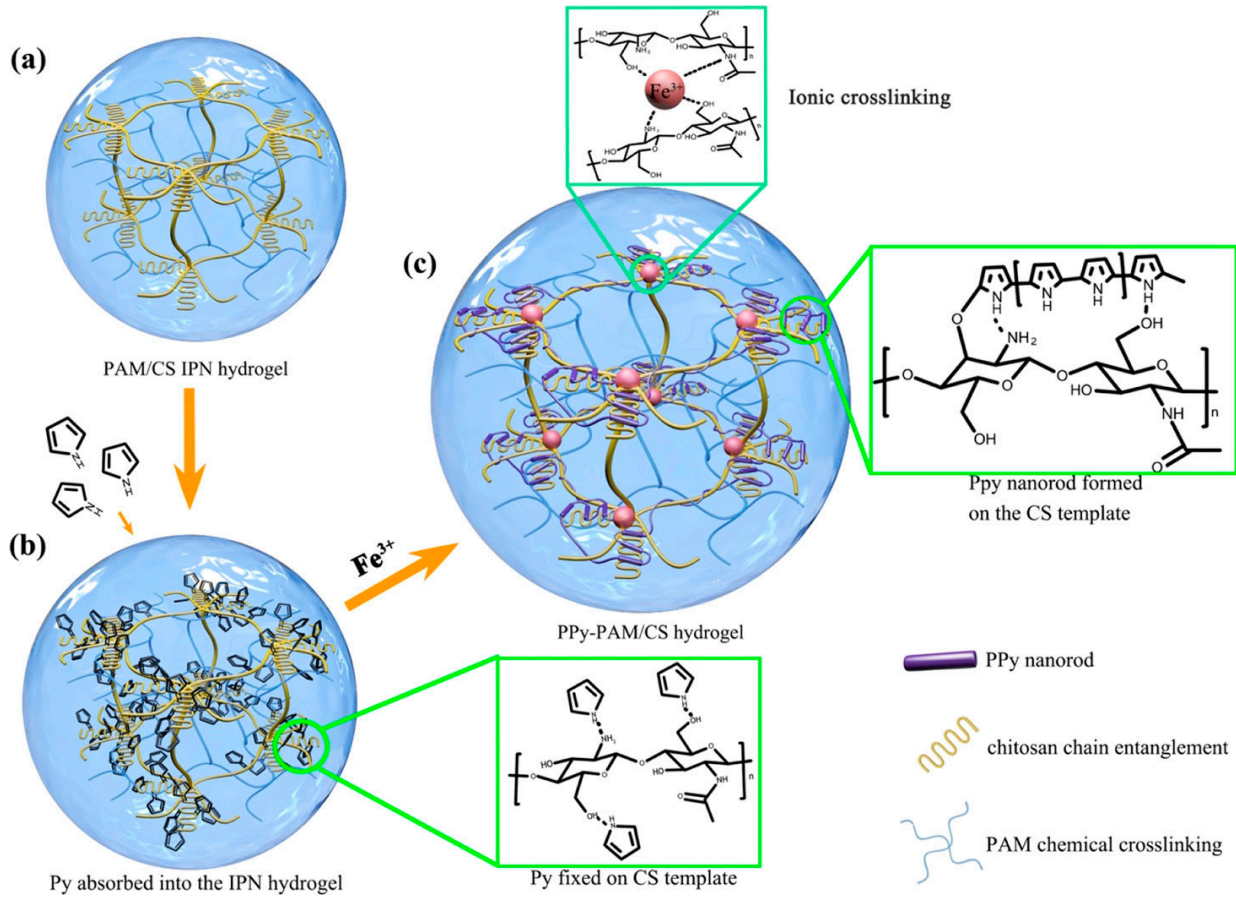

Figure 2. Schematics of the preparation of PPy composited conductive and tough hydrogels; (a) Synthesis of polyacrylamide/chitosan interpenetrating network (PAM/CS IPN) hydrogels; (b) Py absorption into IPN hydrogel fixed on CS chains and accumulated in the CS entanglement zone; (c) PPy in situ polymerization. Adapted with permission from Ref. [59]. Copyright @ 2018 American Chemical Society.

Sponge-based piezoresistive sensors have gained a lot of interest due to their 3D typical porous structure, good elasticity, and large thickness. Low-temperature interfacial polymerization of polypyrene film doped with $\mathrm{FeCl}_{3}$ on a commercial latex sponge as the base material led to a cheap, pressure sensor able to detect human movements (grabbing objects and bending fingers, crouching and standing on tiptoes) [60]. Py monomers were inserted by diffusion into the porous PU elastomer substrates and were in situ polymerized to prepare a stretchable electric material with a thin layer of polypyrrole (PPy) strongly anchored on PU surfaces.

Py monomers were diffused and in situ polymerized into a porous PU elastomer substrate to prepare a stretchable electric material for human breath sensing. The thin layer of polypyrrole (PPy) strongly anchored on PU surfaces led to the formation of net-like microcrack structures that change the electrical resistance of the sensor under stretching and release motions [61].

On an elastic fibrous electrospun PDMS membrane, a PPy layer was applied by vapor phase polymerization to form an "on-off switch" strain sensor. At 0-50\% strain, the sensor showed a normal monotonic resistance response, but at 100-200\% strain, the response mode became "on-off switching" type [62].

Li et al. [63] used a four-step strategy to enhance the stability of PPy coated fabric by chemical vapor deposition of a thin layer of monomer that was polymerized at a low temperature, doped it with a large anion-dodecyl benzene sulfonate, and finally had it annealed. Fabricating a strain sensor on Lycra fibers, Wang et al. [64] showed that the electrically resistance of the sensor was mainly related to the micro-cracks appearing on the fiber surface during deformation. To lower the mechanical and electromechanical hysteresis of the fabric bases sensor, Li et al. proposed to use polyurethane yarns and hybrid polyurethane yarns as fabrics [65]. 


\subsection{Polyaniline}

Polyaniline was successfully polymerized into a nitrile butadiene rubber (NBR) solution. The thin film was used as a stretchable strain sensor. It displayed increased electrical conductivity with the increase of polyaniline filler, but a decrease upon the stretching. This is due to the disconnection mechanism between the filler particles and confirms the theory that PANI can be used as an economical alternative to the more expensive CNT/metal based sensors [66]. Another strategy is a tripolymer composite: polyaniline, polyacrylic acid (PAA), and phytic acid (PA). Due to its high stretchability, self-healing properties and a high electric conductivity, it can be used as a strain and a pressure sensor [67].

A melamine sponge, wrapped in reduced graphene oxide ( $\mathrm{rGO})$ / polyaniline nanowires with tunable sensibility, was able to monitor different body activities, from robust motions (finger bending, elbow and knee movement) to tiny activities (voice recognition, swallowing, mouth opening, gentle/heavy blowing, crying expression and light/deep breathing) [68]. PANI can be used not only to increase the material conductivity, but its reduction performance can be used to reduce $\mathrm{Ag}^{+}$to $\mathrm{Ag}^{0}$, forming particles of metallic silver. Polyester fabric was used as a flexible substrate, and after the polymerization of PANI in situ, the silver was reduced from a solution of silver nitrate. This sensor does not only present rapid response times, high sensitivity, durability and exceptional flexibility, but is also antibacterial due to the presence of silver (Figure 3) [69].

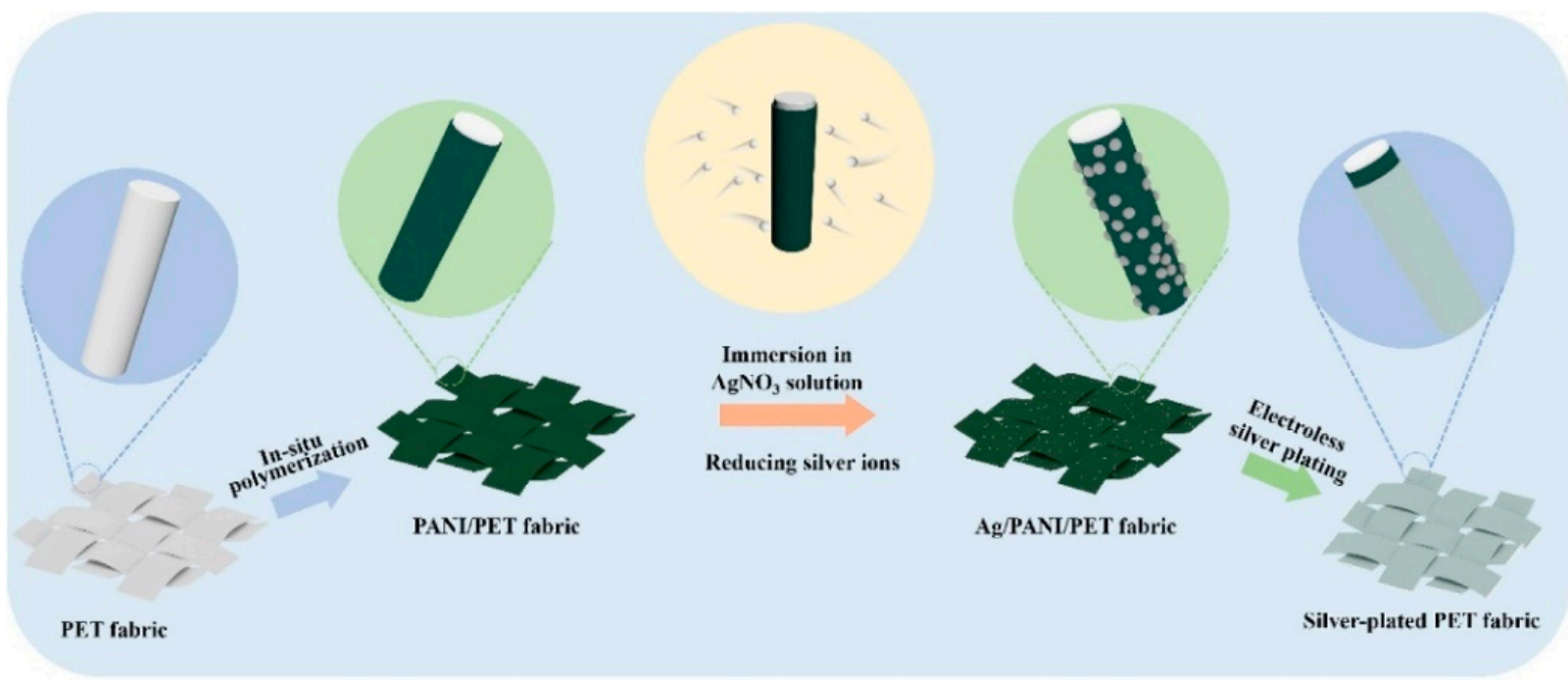

Figure 3. Preparation of silver-PANI sensor. Adapted with permission from Ref. [69]. Copyright@ 2019 Elsevier.

A highly sensitive sensor, capable of noninvasively detecting human pulse waveforms, both from the carotid and the radial arteries (Figure 4A), was proposed by Park et al. The multilayer pressure sensor consists of a top layer of an Au-deposited PDMS micropillar placed on conductive polyaniline nanofibers and a polyethylene terephthalate (PET) substrate. By varying the pressure, changes in contact resistance between Au-coated micropillars and polyaniline take place. Adding to this, a $5 \times 5$ stretchable array on a mixed thin film of PDMS and Ecoflex with embedded liquid metal interconnections, under biaxial stretching (up to 15\%) shows stable sensing of pressure [70].

Patterned poly(vinylidene fluoride) (PVDF) nanofiber-based thin membranes were obtained by electrospinning. Changing the configuration of the patterned collectors, the obtained PVDF membranes had a similar architecture as the electrically conductive collector (sexangular-patterned, nearly rectangle-patterned, metal grid or circular patterned). By chemical oxidative polymerization of aniline, a patterned, highly stretchable, conductive PANI/PVDF nanofibrous membrane with different patterns was obtained and used as a strain sensor that can detect finger motion [71]. Highly aligned PVDF NFs arrays 
integrated within a PANI coated PVDF NFs mat were used as an piezo-organic-e-skin sensor for energy harvesting, from various types of mechanical motion and self-powered human physiological signal sensing. The flexible sensor was able to detect various human gestures, such as neck stretching, wrist bending, arm compressions, and movements of the throat during the drinking of water, coughing actions, and swallowing under couple of conditions such as compression, bending and stretching [72]. For a strain sensor with increased elasticity, Jiang et al. [73] proposed a PU nanofiber membrane prepared by electrospinning, covered by PANI by in situ polymerization, and with silver nanowires fixed by vacuum filtration.

\subsection{PEDOT}

A highly flexible conducive polymer is poly(3,4-ethylenedioxythiophene): poly(styrene sulfonate) (PEDOT:PSS). The PEDOT polymer has shown good conductivity, up to $300 \mathrm{~S} \mathrm{~cm}^{-1}$ when it is oxidatively electropolymerized in the presence of $\mathrm{PF}^{6-}$ counterions, as the resulting material is very resistant to oxygen and water degradation and it has poor solubility, limiting its range of applications. This led to the development of a polyelectrolyte complex, the p-doped and positively charged PEDOT with the negatively charged and water-soluble PSS [74].

A hybrid elastomer/conductive polymer strain sensor was prepared by VPP. Due to the effective diffusion, penetration, and polymerization of the monomer, PEDOT was uniformly dispersed in a thermoplastic polyurethane (TPU). Two types of oxidants were analyzed, $\left(\mathrm{FeCl}_{3}\right.$ and iron (III) p-toluenesulfonate (FTS)), and the FTS-based sensor showed excellent performance in terms of stretchability $(>300 \%)$, gauge factor, resistance and durability. It was shown that the quantity of the dopant is in direct correlation with the quantity of the conductive polymer that was polymerized and, implicitly, with the conductivity of the sensor [75]. Savagatrup et al. [76] analyzed the effect of the commonly used additives dimethylsulfoxide (DMSO), Zonyl fluorosurfactant (Zonyl), and poly(ethyleneimine) (PEI) on the PEDOT:PSS mechanical properties, prepared by spin-coating. Elasticity and ductility were maximized in films deposited from solutions containing 5\% DMSO and 10\% Zonyl and this formulation was used for the preparation of strain sensors. Since the conductivity was observed to be higher in the samples containing $0.1 \%$ Zonyl, that formulation was used for mechanically robust organic solar cells preparation.

Liu et al. [77] fabricated a strain sensor based on poly(3,4-ethylenedioxythiophene) poly(styrenesulfonate)-polyvinyl alcohol (PEDOT:PSS-PVA) nanofibers by electro-spinning on a Kapton substrate. By encapsulating different concentrations of a polydimethylsiloxane layer, the electrical conductivity of the sensor can be easily tuned. Moreover, the sensor presented excellent stability, fast response in detection of finger motion and can be powered by solar cells. Combining the conventional electrospinning with a straightforward, simple harmonic motion, at different speeds, Sun et al. prepared stretchable strain sensors of PEDOT:PSS-poly(vinyl pyrrolidone) fibers with curved architectures [78]. Twisted micropores structures were obtained by twisting the electrospun aligned PEDOT:PSS-polyvinyl pyrrolidone fibers, doped with ionic liquid (1-ethyl-3-methylimidazolium acetate). The presence of the micropores increase the mechanical behavior of the fibers (they can stretch more than $90 \%$ ). This can be used as a tensile sensor, elastic semiconductors and flexible solar cells [79].

A dipping-embedded transfer method was used to prepare a highly conductive stretchable all-plastic wearable sensor. Mild acid was used to increase the conductivity of the layer PEDOT:PSS fabricated on quartz, and it was then embedded into PDMS elastomers. The PEDOT:PSS-PDMS film was used to fabricate two devices, a wearable sensor and a semitransparent organic solar cell (OSCs) [80]. A high-transparency and high-sensitivity capacitive pressure sensor was proposed by Kim et al., with homogeneously and heterogeneously dispersed $\mathrm{SiO}_{2}$ nanoparticles in a diluted PDMS layer on a PEDOT:PSS electrode [81]. 

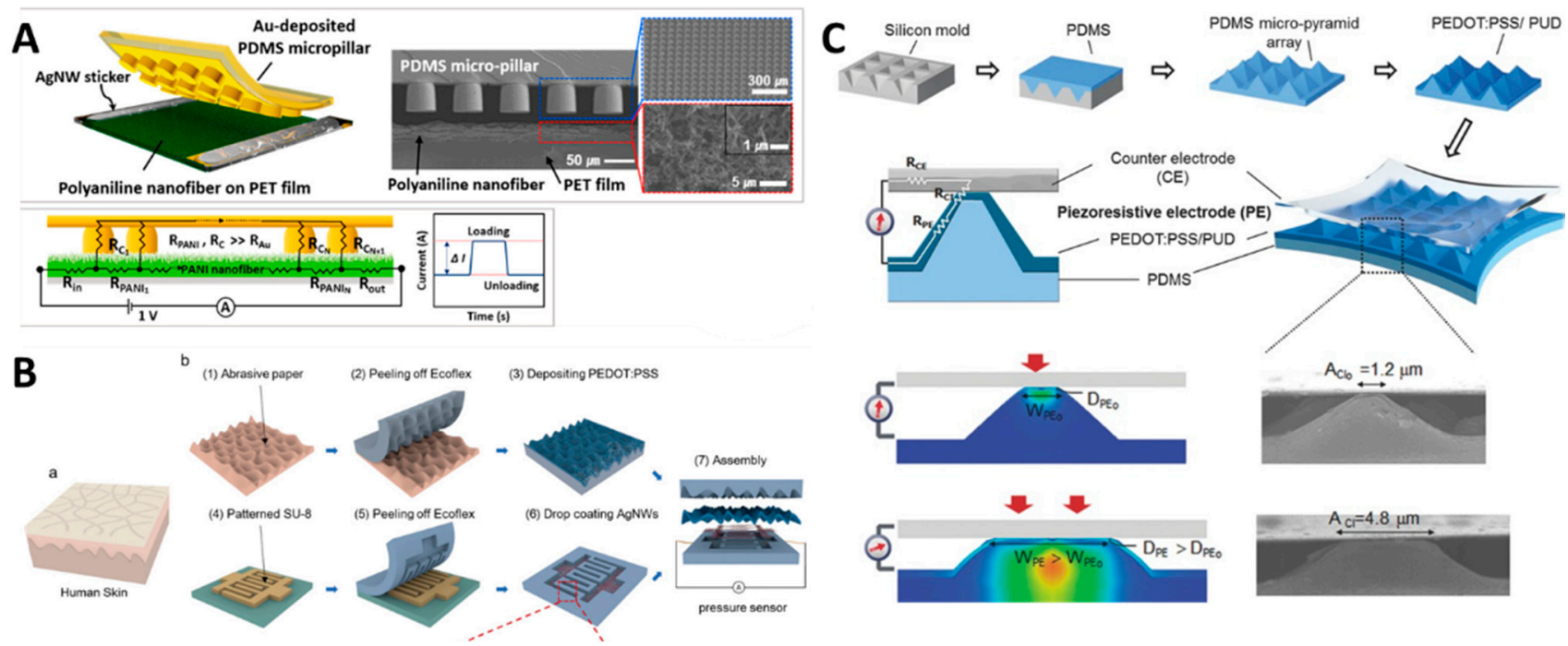

Figure 4. Different types of nanostructures employed to increase the sensor sensibility. (A). Audeposited PDMS micropillars on conductive PANI nanofibers on PET based sensor. (Reproduced from Ref. [70] Copyright (C) 2015 American Chemical Society); (B). Bionic hierarchical structure transferred from abrasive paper based sensor (A-schematic of skin history, B-fabrication process of the sensor), (Reproduced from Ref. [83] Copyright (C) 2019 WILEY-VCH Verlag GmbH \& Co. KGaA, Weinheim); (C). PEDOT:PSS/PUD thin film coating PDMS pyramid surface (Reproduced from Ref. [82] Copyright (C) 2014 WILEY-VCH Verlag GmbH \& Co. KGaA, Weinheim).

Another way to maximize the pressure-induced geometrical change incurred by the conductive electrode, as spring-like compressible micro-pyramid PDMS arrays were deposited as a base. On top, an aqueous polyurethane dispersion (PUD) elastomer blend in the conductive polymer PEDOT:PSS was coated as a potential high-conductivity stretchable electrode. The stretchable pressure sensor presents a higher pressure sensitivity with its elongation, up to $10^{3} \mathrm{kPa}^{-1}$, when it is stretched by $40 \%$ [82] (Figure 4C). On the same idea, high-performance pressure sensors with bionic hierarchical structures were prepared by the peeling of a layer of Ecoflex spin coated from abrasive paper and coated a PEDOT:PSS sensing layer. To enhance the sensitivity of the sensors, a second Ecoflex layer was added (Figure 4B) [83].Table 1 compare the key parameters of these two types PEDOT:PSS based strain flexible sensors with sensors based on PPy or PANI.

Table 1. Comparison of key parameters in different polymer-based strain flexible sensors.

\begin{tabular}{|c|c|c|c|c|c|c|}
\hline Materials & $\begin{array}{l}\text { Response } \\
\text { Time (ms) }\end{array}$ & Sensitivity $\left(\mathrm{kPa}^{-1}\right)$ & $\begin{array}{l}\text { Detection } \\
\text { Limit }(\mathbf{P a})\end{array}$ & $\begin{array}{l}\text { Maximum } \\
\text { Detection } \\
\text { Pressure }\end{array}$ & Voltage (V) & Ref. \\
\hline PEDOT:PSS/AgNWs & 60 & $\begin{array}{c}6.13(<5 \mathrm{kPa}), 0.97 \\
(20-90 \mathrm{kPa})\end{array}$ & 20 & 90 & 0.1 & [83] \\
\hline PEDOT:PSS & NA & $4.88(0.37-5.9 \mathrm{kPa})$ & 13 & 8 & 0.2 & [82] \\
\hline $\begin{array}{c}\text { PPy@poly(vinyl } \\
\text { alcohol-co-ethylene) } \\
\text { nanofibers }\end{array}$ & NA & $\begin{array}{c}1.24(<150 \mathrm{~Pa}), 0.89 \\
(<1 \mathrm{kPa}) \\
0.02(1-7 \mathrm{kPa})\end{array}$ & 1.3 & 7 & 2 & {$[54]$} \\
\hline $\begin{array}{c}\text { PANI nanofibers / Au } \\
\text { deposited } \\
\text { PDMS nanopilars }\end{array}$ & 50 & 2 & 15 & 0.22 & 1 & {$[70]$} \\
\hline
\end{tabular}

The spin-coating method was used to prepare a highly transparent and conductive PEDOT:PSS/Ag nanowires (NWs) composite electrodes for flexible piezoelectric nanogenerator (FPNG). By optimizing the length/diameter ratio of the metallic NWs and its 
volume ratio to PEDOT:PSS, the resulting composite film electrode displayed metallic conductivity, high diffusive transmittance, and highly flexibility [84].

Beneficial synergetic effects were found in the interpenetrated morphology of a network formed with PEDOT:PSS and polyethylene oxide/Zonyl surfactant. The presence of the surfactant increases the ductility and the deposition of the polymer on PDMS elastomer, a hydrophobic surface. The resulting network has an excellent mechanical stretchability and high electrical conductivity that can detect finger motion. As this material is transparent, a power conversion of $12.5 \%$ was registered when used in indium-tin-oxide (ITO)-free solar cells using the PBDB-T-2F:IT-4F blend [18]. Bandodkar et al. [85] used the same surfactant directly mixed in the stretchable Ecoflex substrate of the electrode to decrease the bond unraveling and the delamination of PEDOT:PSS and $\mathrm{Ag} / \mathrm{AgCl}$ printed 2D serpentine interconnections. The conductive polymer ink was used to print the working and the counter electrode while an $\mathrm{Ag} / \mathrm{AgCl}$ reference electrode provided a constant potential. In order to prepare an inkjet-printed PEDOT:PSS-based stretchable conductor for wearable health monitoring applications (photoplethysmography (PPG) and electrocardiography (ECG) recording), Lo et al. [86] systematically studied the effect of various types of polar solvent additives. The optimal ink formulation that induced phase separation and formation of PEDOT and PSS grains, improving the electrical properties, contained 5\% ethylene glycol (EG). For an increased elasticity, poly (ethylene oxide) was added. EG has been used as an antifreeze agent, and can change the freezing point of water below $-40{ }^{\circ} \mathrm{C}$. Rong et al. [87] report an anti-freezing, PEDOT:PSS-PVA strain sensor that is stable in the temperature range -55 to $44.6{ }^{\circ} \mathrm{C}$, owing to the $\mathrm{EG} / \mathrm{H}_{2} \mathrm{O}$ binary sensor.

A sandwich structure containing a nanohybrid film of single-wall carbon nanotubes (SWCNT) between two layers of PU-PEDOT:PSS was analyzed as a strain sensor. The transparent, stretchable, and highly sensitive sensor was able to detect small changes of the human skin when emotional expressions (like crying and laughing) or directional eye movements occurred [88]. Similarly, a three layer sensor formed by a top PEDOT:PSS/SWCNT hybrid electrode array, a bottom PEDOT:PSS/SWCNT hybrid electrode array embedded in the PDMS encapsulation layer, and a PDMS dielectric layer was prepared as a straindiscriminable pressure/proximity sensor [89]. Another sandwich type sensor was prepared for the detection of more ample motion such as joint/muscle motions, arterial pulsation, and voice vibration. The highly conductive PEDOT:PSS film was embedded between a PDMS elastomer sheet and a PEDOT:PSS film doped with poly(vinyl alcohol) (PVA) and Zonyl surfactant. Fine cracks are formed in the conductive polymer by the tensile threads that are getting closer when the film is relaxed, leading to a high sensitivity of the sensor. Moreover, the durability that resulted from the mechanically robust sandwich structure led to the sensor distinguishing complex and diverse bending motions [90].

Rice straw cellulose-derived 2,2,6,6-tetramethylpiperidine-1-oxyl (TEMPO)-cellulose nanofibril (CNF) was protonated and hydrogen bonded with PEDOT/PSS to form a tunable and linearly responsive strain sensor. The PEDOT/PSS/CNF aerogels were up to ten times stronger then the PEDOT/PSS alone due to the transformation of PEDOT benzoid structure to the more electron transfer-preferred quinoid structure. By further vapor annealing of the sensor, with ethylene glycol, the conductivity increased by 2 orders of magnitude. An infusion with poly(dimethylsiloxane) offered the sensitive, linearly responsive strain sensor its stretchable structure [91].

As the sensing property of a strain-based textile sensor is closely related to its structure, fabrication, and to the sensing behavior of its components, Seyedin et al. [92] prepared a strain sensor textile based on conductive polymeric fibers. To avoid the possible mechanical mismatch between the fabric and the conductive coating, highly stretchable PU/PEDOT:PSS fibers were used and knitted in a fiber of four with a commercial Spandex. The knitted textile sensor, combined with a commercial wireless transmitter, showed good response to bending deformation, making it a promising candidate for remote strain sensing applications. 
Kim et al. [93] prepared a microfiber sensor that was used directly as a strain sensor. The highly sensitive and stretchable double-network sensor based of soft polyacrylamide and brittle calcium-alginate microfibers was prepared by microfluidic devices. The resistance of the sensor changed in response to the stretching of the microfiber is due to the connection/partial disconnection of the PEDOT:PSS domains.

Bilayered microcracked PEDOT:PSS films were fabricated to mimic the scales of the snakeskin in order to detect a wide-range of motions. On an elastomer substrate (polydimethylsiloxane [PDMS] or VHB tape), treated with $\mathrm{O}_{2}$ plasma to improve its hydrophilicity and adhesion, a PEDOT:PSS layer was spin coated, baked and uniaxially stretched to form islands (due to the cracks that appeared in the conductive polymer). A second layer of PEDOT:PSS was added, and a biocompatible hydrogel layer was used as an interface between the device and skin. The strain sensor showed excellent results in detecting a wide range of motion, from subtle (pulse and phonation), to mid-level body stretches and joint movements [94]. Asymmetric trilayers based PEDOT:PSS were fabricated as actuating and sensing linear artificial muscles. By using a simple layer stacking process, and combining stiff and soft electrodes, the final material had a sandwich like structure with a ionic liquid 1-ethyl-3-methylimidazolium bis(trifluoromethanesulfonyl) imide (EMImTFSI)poly(ethylene oxide) (PEO)-nitrile-butadiene rubber (NBR) semi-interpenetrating polymer network between two PEDOT:PSS + PEO (40\%) electrodes [95].

The strain sensors can be used not only in health, by monitoring body movements, but can have applications in the food industry, more precisely by developing technology that finds the optimal processing time of starch-based foods. A starch/PEDOT:PSS blend was used to monitor different food preparation processes such as fermentation, storage, steaming, and refreshing of starch-based food. The strain sensor monitoring can lead to a reduced energy consumption and increased quality and productivity in starch-based food industry manufacturing [96].

Gao et al. obtained scalable flexible tactile sensors based on a nanofiber assembly of high-molecular-weight regioregular poly(3-hexylthiophene)(P3HT). Self-standing nanofiber assemblies were formed without the need of high-molecular-weight insulating polymers or highly concentrated solutions (as they are usually required) [97].

Table 1 gives couple of examples of polymer-based strain flexible sensors.

\section{Gas Sensors}

Gases released from natural and industrial processes require detection and monitoring, as they have a tremendous impact on human health.

Gas sensors based on conductive polymer sensing materials have gained interest based on their advantages, such as room temperature operation, tunable conductivity (from insulator to near metallic conductivity) as well as flexibility, low density, environmental stability, low cost and countless ways of functionalization.

A flexible PI substrate with gold interdigital electrodes that was previously hydrophobicitytreated with a poly(dimethyldiallyl ammoniumchloride)(PDDA) solution and poly(sodium 4-styrenesulfonate)(PSS), then a PPy/N-MWCNT hybrid composite film was deposited by in situ self-assembly, followed by chemical polymerization, to obtain a $\mathrm{NO}_{2}$ flexible sensor. After annealing at different temperatures, $T=350{ }^{\circ} \mathrm{C}$ was found to be the ideal temperature. The gas sensor exhibited a high response of $24.82 \%$ under 5 ppm of $\mathrm{NO}_{2}$ and an excellent linear response toward 0.25-9 ppm at room temperature. The enhanced gas sensing performance, after annealing at $350{ }^{\circ} \mathrm{C}$ was attributed to the degradation of an important amount of the stacked PPy, leading to the formation of a large amount of adsorption sites [98].

A common air pollutant is gaseous $\mathrm{NH}_{3}$. In small quantities it is harmless, but in high concentrations can lead to skin and eye irritation, the destruction of the respiratory tract mucosa, and even death. Sources of $\mathrm{NH}_{3}$ in the air are industrial manufacturing, automobile exhaust, animal husbandry or urea manufacturing for agricultural applications. $\mathrm{NH}_{3}$ is also present in the human breath in small quantities (400-14,700 ppb) and its detection can 
be used as a noninvasive clinical diagnostic [99] of hepatic encephalopathy [100], end-stage renal disease (ESRD) [101], halitosis [102] orhelicobacter pylori inflection [103]. The most amply employed conductive polymers for gas sensors are polypyrrole and polyaniline. Figure 5 presents the sensing ammonia mechanism of the PPy and PANi polymers.

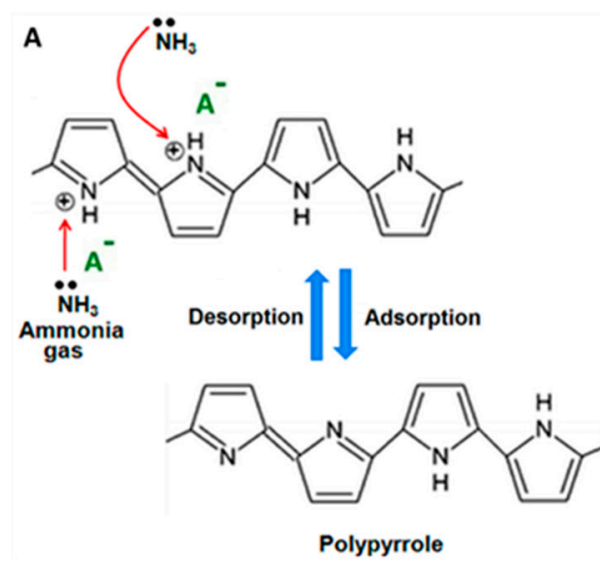

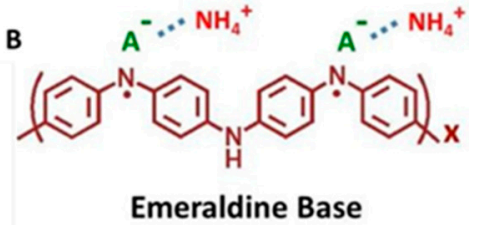

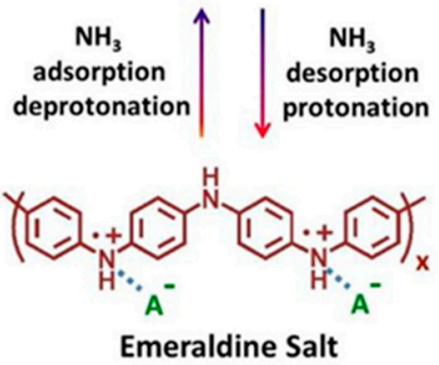

Figure 5. Ammonia sensing mechanism by PPy (A) (Adapted from Ref. [104]. Copyright (C 2017 SciEP) and PANI (B) based gas sensor (Reprinted with permission from Ref. [105] Copyright (c 2020 Elsevier).

Lithographically Patterned Nanowire Electrodeposition was used to fabricate onedimensional, long $(>1 \mathrm{~cm})$, complex nanoribbons on 4 inch silicon/silicon dioxide wafers and flexible polyimide. This chemical gas sensors, based on chemo resistive response to ammonia vapor, has a controllable sensitivity by tuning the functional groups on the $\mathrm{Py}\left(-\mathrm{NH}_{2}\right.$ and $\left.-\mathrm{COOH}\right)$, the dopants (sodium dodecyl sulfate) or by employing different catalysts that decorate the conductive polymer ( $\mathrm{Au}, \mathrm{Pd})$ [106]. One other dopant that was shown to improve the sensitivity of an ammonia gas sensor is lithium perchlorate. PPy-percolation networks were electropolymerized between Au interdigitated electrodes on flexible PET substrates [107].

Two flexible substrates, silk-fiber and sponge, were compared for the fabrication of a pyrrole based gas sensor. The PPy film was prepared via the in situ chemical oxidation method using silica nanospheres as a template. The response of the PPy/NS@silk-fiber sensor (73.25\%) was five-fold higher than that of the PPy/NS@sponge sensor (14.51\%), when exposed to $100 \mathrm{ppm} \mathrm{NH}_{3}$, in $(68 \pm 5) \%$ relative humidity, at room temperature [108]. Sulfonated poly(ether-ether ketone) (SPEEK) and polyacrylonitrile were used as a core for PPy nanofibers based gas sensors in order to improve the mechanical flexibility and to facilitate ammonia diffusion in the film [109].

Ammonia gas sensors based on PANI-polyethylene terephthalate (PET) flexible substrates were prepared by a simple in situ polymerization technique at different temperatures $[110,111]$. The room-temperature-functioning, highly sensitive, flexible and transparent sensor showed mechanical stability and flexibility after repetitive bending cycles [110].

PANI was observed to have a dual role in enhancing flexibility as well as improving the sensor performance towards ammonia. MWCNTs were spray coated on a polypropylene woven fabric, and then PANI was chemically polymerized in situ for wearable ammonia sensors with low detection limits [112]. By controlling the reaction parameters in the in situ polymerization of PANI, Qi et al. [113] prepared a highly sensitive ammonia sensor on non-woven fabric by creating nanostructures in the polymer film.

The effect of different acids used as dopants, was analyzed by Hong et al. [114]. The PANI-nylon 6 composite sensors, using monocarboxylic acids (acrylic acid, formic acid, trichloroacetic acid) showed fast response and excellent sensitivity. $\mathrm{CeO}_{2}$ is considered to have a good acidic stability and was shown to improve the protonation and oxidation 
degree on PANI composite film on a PI flexible substrate. The synergetic oxidation of $\mathrm{CeO}_{2}$ nanoparticles and ammonium persulfate offered the sensor a reduced recovery time and good reproducibility, selectivity, and stability (500 bending/extending cycles), as well as an ultra-low detectable concentration of ammonia (16 ppb) [115].

PANI-based sensors have shown the most promising results for the detection of ammonia, and PANI composites are being used on different flexible substrates such as:

- $\quad$ PET: camphor sulfonic acid-doped PANI/ $\alpha-\mathrm{Fe}_{2} \mathrm{O}_{3}$ (PFC) [116], inkjet-printed polyanilinedodecyl benzenesulfonic acid nanoparticles deposited onto screen-printed silver interdigitated electrodes, [117] rGO-PANI hybrids [118], composite nanostructured films, hierarchically nanostructured PANI covering a transparent conducting film of carbon nanotube (CNT) networks, [119] or nontransparent CNT [120] or rGO, [115] S and N co-doped graphene quantum dots-PANI composite film [121], metal oxide-PANI composite (Iron oxide, [122] ferric oxide, [123] tin oxide, [124] zinc oxide [125]), interdigital electrodes carbon based printed on an active PANI film [126]; rambutan-like polyaniline hollow nanosphere and graphene oxide, [127] PANI polymerized-electrospun poly(methyl methacrylate) on Au/Ni interdigitated electrode [128];

- Vertical contact-separate mode triboelectric nanogenerators (TENG) based on PANIMWCNTs composite thin [129] or on PANI-two dimensional (2D) niobium carbide MXene $\left(\mathrm{Nb}_{2} \mathrm{CT}_{x}\right)$ [130];

- $\quad$ Polyimide (PI): PANI/ $\mathrm{SrGe}_{4} \mathrm{O}_{9}$ nanocomposites (PSN) via the in situ chemical oxidation polymerization method on seven pairs of Au interdigitated electrodes [131];

- Silicon dioxide: PANI-coated titanium dioxide or copper oxide-titanium dioxide [132], $\mathrm{CeO}_{2}$ decorated PANI nanofibers [133] on bacterial cellulose: a dodecylbenzene sulfonic acid (DBSA) and poly(2-acrylamido-2-methyl-1-propane sulfonic acid) (PAMPS) doped PANI composite [105];

- $\quad$ Flexible porous polyvinylidene fluoride (PVDF): PANI film with PSS as additive [134];

- On twistable and tailorable nanocomposites (NCPs) textiles: graphene oxide-aniline polymerized in situ by vanadium pentoxide [135];

- Cellulose acetate nanofibers, prepared by electrospinning, followed by deacetylation. On these regenerated cellulose fibers, titanium dioxide nanoparticles were absorbed followed by in situ polymerization of aniline [136].

PEDOT and PSS are also employed for the preparation of ammonia gas sensors. Hydrogel sensors based on PEDOT:PSS/ $\mathrm{IrO}_{\mathrm{x}}$ particles deposited on a flexible plastic foil were recently successfully tested as an ammonia sensor. The sensors were tested in a wearable configuration with wireless connectivity to a smartphone and showed stability to mechanical deformations and good analytical performances [137]. PVA electrospun nanofibers covered by PEDOT by VPD on a flexible paper filter substrate, [138] PEDOT:PSS thermal inkjet printed on photographic paper, covered by aluminum interdigitated electrodes [139], graphene-PEDOT:PSS inkjet printed on silver interdigitated electrodes, [140], and in situ self-assembly polymers of two-cycle poly(4-styrenesulfonic acid) sodium salt/poly(allylamine hydrochloride) (PSS/PAH) bilayers on an organic monolayer (3-mercapto-1-propanesulfonic acid sodium salt-MPS) on comb-like Au/Cr electrodes [141] have also been reported.

Hydrogen is a flammable, odorless and hazardous gas, but as the car industry is evolving, it is more and more present due to its link to fuel cells. A layer of PPy was modified with platinum particles by immersion of the sensor in $\mathrm{PtCl}_{6}{ }^{2-}$ followed by reduction with $\mathrm{NaBH}_{4}$ and the layer-by-layer formed sensor was tested as a hydrogen gas sensor [142].

A stretchable and transparent electrochemical sensor formed by binding SWNT with PEDOT showed good results in a real-time monitoring of biochemical signals (NO re-lease) from mechanically stretched cells. The coating of the SWNT with the conducting polymer reduced contact resistance and improved the electrochemical performance of the sensor overall [143]. 
Nitrogen dioxide, $\mathrm{NO}_{2}$, is related to the formation of acid rain. PPy coated $\mathrm{SnO}_{2}$ nanoparticles film on $\mathrm{Au} / \mathrm{Cr}$ integrated electrodes, placed on a PET flexible substrate, was employed as a gas sensor to detect low concentrations of $\mathrm{NO}_{2}(0.5-5 \mathrm{ppm})$ at room temperature [144]. $\mathrm{A} \mathrm{WO}_{3}$-PEDOT:PSS nanocomposite was fabricated on $\mathrm{Ag}$ interdigitated electrodes on a PI substrate by gravure printing for the detection of $\mathrm{NO}_{2}$ gas, at room temperature, for real-time environmental monitoring [145].

Volatile organic compounds (VOCs) are organic compounds with a high vapor pressure at room temperature. Besides their harmful effect on health in large quantities, they are also considered as markers for several diseases, as well as in the quality of food and air. Ethanol vapors represent a carcinogenic risk in the workplace. The occupational exposure limit is 500 ppm (in Germany) and 1000 ppm (in France and USA). Bahoumina et al. [146] proposed a real-time monitoring and quantification of ethanol by a flexible Kapton substrate with a PEDOT:PSS-MWCNTs ink as the conductive layer. As the adsorption of ethanol vapors changes the conductivity of the detection layer, the resonance frequency and amplitude shift. This microwave flexible gas sensor is suitable for wireless applications.

Almukhlif et al. [147] prepared a sensor for the detection of liquefied petroleum gas. On a PET substrate a novel nano-heterojunction between p-PEDOT-PSS and tin oxide $\left(n-\mathrm{SnO}_{2}\right)$ treated with DMSO and PVA was formed, employing the spin coating technique followed by treatment with sulfuric acid. The presence of DMSO and PVA have an effect of increasing Young's modulus and tensile strength, while the acid enhanced the conductivity of the film.

PPy and PANI showed a good sensitivity and selectivity towards ammonia (Table 2). When polypyrrole or polyaniline are exposed to ammonia, the lone pair of electron on the $\mathrm{N}$ atom is accepted by holes of the polymers. This results in a drop in the charge concertation CPs ( $p$-type semiconductors) leading to a conductivity decrease. Usually, $n$-type dopants are added in order to narrow the conductive path of the CPs and to increase their protonation degree.

Aside from sensing ammonia, other gases such as $\mathrm{NO}_{2}, \mathrm{NO}, \mathrm{H}_{2}, \mathrm{H}_{2} \mathrm{~S}, \mathrm{Cl}_{2}, \mathrm{CO}$ and VOCs were also investigated (Table 3 ). VOCs are numerous, varied, and ubiquitous. The VOCs gas sensors are generally based on modified metal oxides and carbon-based material [44]. However, some examples of flexible gas sensors based on conductive polymers are present in the literature (Table 3).

MPS-3-Mercapto-1-propanesulfonic acid sodium salt, PAH-poly(allylamine hydrochloride, PSS-poly(styrenesulfonic acid); BOPET-biaxially-oriented polyethylene terephthalate, PI-polyimide, PP-polypropylene, PET-polyethylene, PCDTBT-poly[N-9'-heptadecanyl-2,7-

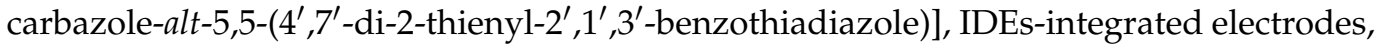
LPNE-Lithographically Patterned Nanowire Electrodeposition CA-chronoamperometry, NS-nanospheres, SPEEK-sulfonated poly(ether ether ketone), PAN-Polyacrylonitrile, GQDsgraphene quantum dots; VDP vapor deposition polymerization, TIJ-thermal ink-jet printing technique; LBL-layer by layer; FMWCNT-functional multiwalled $\mathrm{CNT}, \mathrm{Nb}_{2} \mathrm{CT}_{\mathrm{x}}$-niobium carbide MXene., FR4-flame-retardant substrate, FeTPPCl-10,15,20-tetraphenyl-21H,23Hporphyrin iron(III) chloride, GQDs-graphene quantum dots, Pc-Phthalocyanine, LBGliquefied petroleum gas, DMF-N, N-Dimethylformamide.

The sensitivity $S$ of a gas sensor is defined as the normalized resistance change

$$
S=\left(R_{\mathrm{g}}-R_{0}\right) / R_{0}=\Delta R / R_{0}
$$

where $R_{\mathrm{g}}$ is the resistance of the conductive film/sensor after the exposure to the gas analytes and $R_{0}$ is the resistance in air. 
Table 2. Flexible gas sensors.

\begin{tabular}{|c|c|c|c|c|c|}
\hline Target Gas & Substrate & Polymer Based Sensing & Fabrication Technique & $\begin{array}{l}\text { Sensibility } \\
\qquad \mathrm{Cg} ; S\end{array}$ & Ref. \\
\hline \multirow{22}{*}{$\mathrm{NH}_{3}$} & PI/Si wafers & PPy nanoribbons & LPNE & $1 \mathrm{ppm}, 80 \%$ & [106] \\
\hline & PET/Au-IDEs & PPy networks & $\mathrm{CA}, 1.3 \mathrm{~V}$ & $0.01 \mathrm{ppm}, 39.4 \%$ & [107] \\
\hline & PET & $\mathrm{PPy} / \mathrm{rGo}$ & In situ polymerization & $10 \mathrm{ppm}, 50 \%$ & [148] \\
\hline & PET & PPy & LBL & $50 \mathrm{ppm}, 77.75 \%$ & [141] \\
\hline & Silk & PPy & $\begin{array}{l}\text { In situ polymerization, } \\
\mathrm{SiO}_{2} \mathrm{NS} \text { template }\end{array}$ & $1 \mathrm{ppm}, 73.25 \%$ & [108] \\
\hline & PI/Au-IDEs & $\begin{array}{l}\mathrm{PANI} / \mathrm{SrGe}_{4} \mathrm{O}_{9} \\
\text { nanocomposites }\end{array}$ & In situ polymerization & $0.2-10$ ppm, 20.59\% & [131] \\
\hline & PAN fibers & $\begin{array}{c}\text { SPEEK/PPy } \\
\text { core-shell nanofibers }\end{array}$ & $\begin{array}{l}\text { Electrospinning, } \\
\text { solution-phase } \\
\text { polyamidation }\end{array}$ & $20 \mathrm{ppb}, 3.8 \%$ & [109] \\
\hline & PET & PANI film & In situ polymerization & 25 ppm, 3.86\% & [110] \\
\hline & PET & PANI & In situ polymerization & $100 \mathrm{ppm}, 26 \%$ & [111] \\
\hline & PP-woven fabric & PANI/MWCNTs & In situ polymerization & 20 ppm, $61.54 \%$ & [112] \\
\hline & PET & PANI/CNT & In situ polymerization & 50 ppm, $25 \%$ & [120] \\
\hline & PI/Au-IDEs & $\mathrm{PANI} / \mathrm{CeO}_{2}$ & In situ self-assembly & $\begin{array}{r}10-50 \mathrm{ppm}, \\
106.9-262.7 \%\end{array}$ & [149] \\
\hline & PET & $\mathrm{PANI} / \alpha-\mathrm{Fe}_{2} \mathrm{O}_{3}$ & In situ polymerization & 100 ppm, 39\% & [122] \\
\hline & PET & $\begin{array}{c}\text { CSA doped } \\
\text { PANI } / \alpha-\mathrm{Fe}_{2} \mathrm{O}_{3}\end{array}$ & In situ polymerization & 100 ppm, $72 \%$ & [116] \\
\hline & PET & PANI/S,N, GQDs & $\begin{array}{l}\text { Drop casting, in situ } \\
\text { polymerization }\end{array}$ & 100 ppm, $42 \%$ & [121] \\
\hline & Filter paper & PEDOT Nanotubes & VDP & $60 \mathrm{ppm},<30 \%$ & [138] \\
\hline & Photo paper & PEDOT/PSS & TIJ & $100 \mathrm{ppm},<35 \%$ & [139] \\
\hline & $\begin{array}{c}\text { Transparent } \\
\text { substrate/Ag IDEs }\end{array}$ & PEDOT/PSS & Inkjet printing & 500 ppm, 9.6\% & [140] \\
\hline & PET/Ag-C IDEs & PANI NPs & Inkjet printing & 100 ppm, 70\% & [117] \\
\hline & PET & $\mathrm{PANI} / \mathrm{rGO}$ & In situ polymerization & $100 \mathrm{ppm},<35 \%$ & [118] \\
\hline & PET & PANI/FMWCNT & In situ polymerization & 100 ppm, $30 \%$ & [119] \\
\hline & PET/Au-IDEs & $\mathrm{PANI} / \mathrm{Nb}_{2} \mathrm{CT}_{\mathrm{x}}$ & In situ polymerization & $10 \mathrm{ppm},<60 \%$ & [130] \\
\hline
\end{tabular}

Table 3. Flexible gas sensors aside from ammonia.

\begin{tabular}{|c|c|c|c|c|c|}
\hline Target Gas & Substrate & Polymer Based Sensing & Fabrication Technique & $\begin{array}{l}\text { Sensibility } \\
\qquad g ; S\end{array}$ & Ref. \\
\hline \multirow{6}{*}{$\mathrm{NO}_{2}$} & PET/Cr-Au IDEs & PPy/(PSS/PAH)/MPS & LBL & 5 ppm, $19.16 \%$ & [141] \\
\hline & & & In situ & & \\
\hline & PI & PPy/N-MWCNT & self-assembly/annealing & $<5$ ppm; $24.82 \%$ & [98] \\
\hline & & & treatment & & \\
\hline & BOPET & PCDTBT & \multirow{2}{*}{$\begin{array}{c}\text { Spin coating } \\
\text { In situ polymerization, } \\
\mathrm{SiO}_{2} \mathrm{NS} \text { template }\end{array}$} & 100 ppm, $2 \%$ & [150] \\
\hline & Silk & PPy & & 100 ppm, 8.9\% & [108] \\
\hline $\mathrm{NO}$ & BOPET & PCDTBT & Spin coating & $100 \mathrm{ppm}, 80.6 \%$ & {$[150]$} \\
\hline \multirow{2}{*}{$\mathrm{H}_{2}$} & PET & $\mathrm{PPy} / \mathrm{Pt}$ NPs & LBL & 1000 ppm, 22\% & [142] \\
\hline & $\mathrm{PET} / \mathrm{Cr}-\mathrm{Au}$ IDEs & PPy/(PSS/PAH)/MPS & LBL & 1000 ppm, $0.46 \%$ & [141] \\
\hline \multirow{2}{*}{$\mathrm{H}_{2} \mathrm{~S}$} & FR4/Ni-Cu IDEs & $\mathrm{PANI} / \mathrm{ZnO}$ & In situ polymerisation & $100 \mathrm{ppb}, 3.2 \%$ & [151] \\
\hline & BOPET & PCDTBT & Spin coating & $100 \mathrm{ppm}, 2 \%$ & [150] \\
\hline $\mathrm{Cl}_{2}$ & BOPET & PCDTBT & Spin coating & 100 ppm, 2.2\% & [150] \\
\hline \multirow{3}{*}{$\mathrm{CO}$} & PE/Au-IDEs & PPy-FeTPPCl & Spin-coated & 300 ppm, $6.8 \%$ & [152] \\
\hline & $\mathrm{PET} / \mathrm{Cr}-\mathrm{Au}$ IDEs & PPy/(PSS/PAH)/MPS & LBL & 200 ppm, $0.21 \%$ & [141] \\
\hline & BOPET & PCDTBT & Spin coating & 100 ppm, $2.1 \%$ & [150] \\
\hline
\end{tabular}


Table 3. Cont.

\begin{tabular}{|c|c|c|c|c|c|}
\hline Target Gas & Substrate & Polymer Based Sensing & Fabrication Technique & $\begin{array}{l}\text { Sensibility } \\
\qquad g ; S\end{array}$ & Ref. \\
\hline \multirow{6}{*}{ Acetone } & PET & ZnO/GQDs-S,N/PANI & Drop-casting & $0.5 \mathrm{ppm}, 2 \%$ & [153] \\
\hline & $\mathrm{PET} / \mathrm{Ag}$ IDEs & $\mathrm{WO}_{3} /$ PANI & Drop-casting & 100 ppm, $6.5 \%$ & [154] \\
\hline & Fabric & PANI & LBL & 50 ppm, $24 \%$ & [113] \\
\hline & PI/Cu-IDEs & $\mathrm{PANI} / \mathrm{Ni}-\mathrm{Pc}$ & Chemical polymerization & $150 \mathrm{ppm}, 50 \%$ & [155] \\
\hline & Silk & PPy & $\begin{array}{c}\text { In situ polymerization, } \\
\mathrm{SiO}_{2} \mathrm{NS} \text { template }\end{array}$ & 100 ppm, $1.14 \%$ & [108] \\
\hline & PP-woven fabric & PANI/ MWCNTs & In situ polymerization & 100 ppm, $12.67 \%$ & [112] \\
\hline \multirow[b]{2}{*}{ Methanol } & PE & PPy & Ink-jet & 5000 ppm, $88 \%$ & {$[156]$} \\
\hline & PP-woven fabric & PANI/ MWCNTs & In situ polymerization & 100 ppm, $8.37 \%$ & {$[112]$} \\
\hline \multirow{6}{*}{ Ethanol } & $\mathrm{PE}$ & PPy & Ink-jet & $5000 \mathrm{ppm}, 68 \%$ & [156] \\
\hline & Fabric & PANI & LBL & 32.5 ppm, $65 \%$ & [113] \\
\hline & $\mathrm{PI} / \mathrm{Cu}-\mathrm{IDEs}$ & $\mathrm{PANI} / \mathrm{Cu}-\mathrm{Pc}$ & Chemical polymerization & 150 ppm, 32\% & [155] \\
\hline & BOPET & PCDTBT & Spin coating & 100 ppm, $1.8 \%$ & [150] \\
\hline & Silk & PPy & $\begin{array}{l}\text { In situ polymerization, } \\
\mathrm{SiO}_{2} \mathrm{NS} \text { template }\end{array}$ & $100 \mathrm{ppm}, 0.84 \%$ & [108] \\
\hline & PP-woven fabric & PANI/ MWCNTs & In situ polymerization & 100 ppm, $10.45 \%$ & {$[112]$} \\
\hline Propanol & $\mathrm{PE}$ & PPy & Ink-jet & 5000 ppm, 55\% & [156] \\
\hline \multirow[b]{2}{*}{ Iso-propanol } & $\mathrm{PI} / \mathrm{Cu}-\mathrm{IDEs}$ & $\mathrm{PANI} / \mathrm{Fe}-\mathrm{Pc}$ & Chemical polymerization & $150 \mathrm{ppm}, 45 \%$ & [155] \\
\hline & PP-woven fabric & PANI/MWCNTs & In situ polymerization & 100 ppm, $6.97 \%$ & [112] \\
\hline n-butanol & PP-woven fabric & PANI/MWCNTs & In situ polymerization & 100 ppm, 8.91\% & {$[112]$} \\
\hline \multirow{2}{*}{ Chloroform } & $\mathrm{PE}$ & PPy & Ink-jet & 5000 ppm, 40\% & [156] \\
\hline & PP-woven fabric & PANI/MWCNTs & In situ polymerization & $100 \mathrm{ppm}, 14.5 \%$ & [112] \\
\hline Ethanediol & Silk & PPy & $\begin{array}{c}\text { In situ polymerization, } \\
\mathrm{SiO}_{2} \mathrm{NS} \text { template }\end{array}$ & 100 ppm, $1.07 \%$ & {$[108]$} \\
\hline Ether & Silk & PPy & $\begin{array}{l}\text { In situ polymerization, } \\
\mathrm{SiO}_{2} \mathrm{NS} \text { template }\end{array}$ & 100 ppm, $0.47 \%$ & {$[108]$} \\
\hline Formaldehide & PI/Cu-IDEs & $\mathrm{PANI} / \mathrm{Zn}-\mathrm{Pc}$ & Chemical polymerization & $150 \mathrm{ppm}, 260 \%$ & [155] \\
\hline \multirow{2}{*}{ Benzene } & PE & PPy & Ink-jet & 5000 ppm, 30\% & [156] \\
\hline & PP-woven fabric & PANI/MWCNTs & In situ polymerization & 100 ppm, $7.84 \%$ & [112] \\
\hline Xylene & PP-woven fabric & PANI/MWCNTs & In situ polymerization & $100 \mathrm{ppm}, 11.03 \%$ & [112] \\
\hline Cyclohexane & Silk & PPy & $\begin{array}{l}\text { In situ polymerization, } \\
\mathrm{SiO}_{2} \mathrm{NS} \text { template }\end{array}$ & 100 ppm, 0.85\% & {$[108]$} \\
\hline Trichloromethane & Fabric & PANI & LBL & 90 ppm, $150 \%$ & [113] \\
\hline Ethyl acetate & Fabric & PANI & LBL & 75 ppm, 5.5\% & [113] \\
\hline Acetyl acetone & Silk & PPy & $\begin{array}{l}\text { In situ polymerization, } \\
\mathrm{SiO}_{2} \mathrm{NS} \text { template }\end{array}$ & 100 ppm, 3.85\% & [108] \\
\hline \multirow{3}{*}{ Toluene } & Fabric & PANI & LBL & $32.5 \mathrm{ppm}, 45 \%$ & [113] \\
\hline & Silk & PPy & $\begin{array}{l}\text { In situ polymerization, } \\
\mathrm{SiO}_{2} \mathrm{NS} \text { template }\end{array}$ & 100 ppm, $0.24 \%$ & {$[108]$} \\
\hline & PP-woven fabric & PANI/MWCNTs & In situ polymerization & 100 ppm, 9.42\% & [112] \\
\hline LPG & PET & PEDOT/PSS & Spin coating & 100 ppm, 79\% & [147] \\
\hline DMF & Silk & PPy & $\begin{array}{c}\text { In situ polymerization, } \\
\mathrm{SiO}_{2} \mathrm{NS} \text { template }\end{array}$ & 100 ppm, $0.89 \%$ & [108] \\
\hline
\end{tabular}

$\mathrm{Cg}$-concentration of the target gas, S-sensibility.

\section{4. $\mathrm{pH}$ and Ions Sensors}

There are multiple health problems that are correlated with $\mathrm{pH}$ changes in the human organism, like mental health disorders, cardiovascular disease or cancer and diabetes. A rapid and efficient treatment may be possible by means of early and real time detection of $\mathrm{pH}$ variation [157]. The healing process of chronic wounds is correlated with their $\mathrm{pH}$ level. Thus, the local pH determination in real time is important. Rahimi et al. [158], fabricated an inexpensive flexible $\mathrm{pH}$ sensor array on a polymer-coated commercial paper (palette paper). Each individual sensor consists of two screen-printed electrodes, the reference electrode $\mathrm{Ag} / \mathrm{AgCl}$, and a WE carbon electrode coated with a PANI membrane. A highly stretchable 
(up to 135\%) electrochemical $\mathrm{pH}$ sensor for wearable point-of care applications is reported by the same group [159]. The sensor was fabricated by combining irreversible bonding of the polyimide to an Ecoflex elastomeric substrate by salinization, followed by laser carbonization of serpentine carbon traces, a low-cost technique, thus eliminating the need for photolithographic micropatterning and nanomaterial deposition. These highly porous carbonized 2D structures were permeated with PANI as the conductive filler, binding and $\mathrm{pH}$ sensitive material. As the sensor is biocompatible, it can be used as a stretchable $\mathrm{pH}$ sensor for wound infection monitoring. Following the same idea, Park et al. [160] prepared a two-electrode configuration $\mathrm{pH}$ sensor consisting of an $\mathrm{Ag} / \mathrm{AgCl}$ reference electrode and a PANI nanofiber carbon array-based sensing electrode. The silver and the carbon electrodes were prepared by a simple screen-printing process on PET substrate, and PANI nanofibers were prepared through a dilute chemical polymerization method. To increase the conductivity of the PANI film, Li et al. used dodecyl benzene sulfonic acid as dopant [161]. The polyaniline film was electrospun on interdigitated electrodes etched on polyimide film based on Micro-Electro-Mechanical System fabrication technologies.

In order to measure $\mathrm{pH}$ in small volumes of human fluid (sweat, saliva, tears, urine), Yoon et al. [162] prepared a robust and self-healing $\mathrm{pH}$ sensor by weaving two carbon fiber threats electrodes and coating it with a self-healing polymer (SHP). The $\mathrm{pH}$ sensing fiber was prepared by electropolymerization of PANI and the reference electrode fiber was prepared by coating the carbon fiber with an $\mathrm{Ag} / \mathrm{AgCl}$ ink (Figure 6). Poly(1,4cyclohexanedimethanol succinate-co-citrate), the SHP, was able to successfully heal mechanical damages (efficiency up to $98 \%$ after 4 cycles of cutting and healing). Moreover, the high flexibility and thinness of the $\mathrm{pH}$ sensor makes it eligible for incorporation in clothing, resulting in a wearable $\mathrm{pH}$ sensing system.

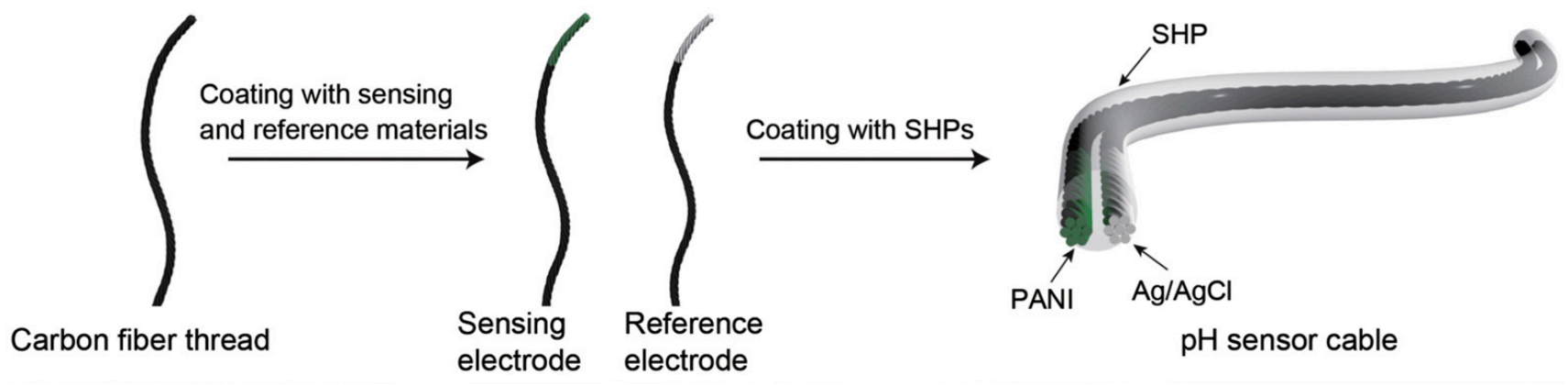

Figure 6. Schematic representation of a $\mathrm{pH}$ sensor cable based on a PANI $\mathrm{pH}$ sensing electrode and $\mathrm{Ag} / \mathrm{AgCl}$ reference electrode, coated with a self-healing polymer. Adapted with permission from Ref. [162]. Copyright (C) 2019 Elsevier.

Stretchable sensor arrays based on vertically aligned mushroom-like gold nanowires on PDMS flexible substrate were used for the preparation of the ion and $\mathrm{pH}$ tattoo like sensor. On a PANI layer, a polyvinyl chloride based selective membrane containing sodium ionophore $\mathrm{X}$ (for $\mathrm{Na}^{+}$detection) and valinomycin (for the detection of $\mathrm{K}^{+}$) was added by drop casting. The sensor was integrated with a flexible printed circuit board for a wireless on-body detection of $\mathrm{pH}$ and ions [163].

Electrically conducting fiber electrodes prepared by wet spinning a PEDOT:PSS solution were coated with polyaniline. Different treatments of the polymeric fibers with DMSO, sulfuric acid and formic acid were analyzed. The optimal balance of electrical conductivity and mechanical strength for a $\mathrm{pH}$ sensor was found for the fibers treated with DMSO [164]. Kim et al. [165] fabricated a microfiber-based substrate-free organic electrochemical transistor by wet-spinning (OECTs). The PEDOT:PSS microfibers used a sulfuric acid-based coagulation medium together with a source-gate hybrid electrode forming a sensor to perform real-time, repetitive measurements of the total cation concentrations in human sweat samples. 
Mariani et al. [166] designed an electrochemically gated organic semiconductor $\mathrm{pH}$ sensor, combining the robustness of a potentiometric-like transduction with the simple and integrated geometry of thin polymeric films with a pH-sensitive layer (PEDOT:BTB). A second polymeric layer acting as a charge transport layer allows a label-free detection of $\mathrm{pH}$ and eliminates the need for an ion-selective membrane [167].

\section{Biosensors}

Extensive research has focused on the development of different types of biosensors, for an array of applications, from detection of bio-threat risks and toxins in food to medical diagnostics. Nanostructures increase the sensitivity of the sensors by increasing the surface area. Using an electro-spun nylon fiber mat, a highly conductive copolymer Poly (EDOT and 3-thiopheneethanol) was deposited by oxidative chemical vapor deposition, forming a nanofiber mat. On the free -OH groups of the copolymer, avidin biomolecules were covalently immobilized for the detection of biotin in nano-molar concentrations [168]. A woven fiber electrochemical transistor for glucose detection has been fabricated based on reduced graphene oxide sheets. Polypyrrole nanowires were incorporated into rGO sheets by a facile in situ polymerization. The glucose sensors exhibited outstanding sensitivity and selectivity, with a fast response time $(0.5 \mathrm{~s})$, a linear range of $1 \mathrm{nM}$ to $5 \mu \mathrm{M}$, a low detection concentration and good repeatability [169].

An enzymatic glucose sensor was printed on a disposable paper substrate via inkjet. Two PEDOT:PSS printed layers were used as a reference, working and counter electrode. The biological coating, containing glucose oxidase and the mediator, ferrocene, was printed on the working electrode and on top of the sensor a layer of nanofilm to protect the sensor [170]. Cai et al. [171] proposed a single-step modification of a nanostructured (PANI) / glucose oxidase (GOD) enzyme on double-sided, screen-printed, flexible electrodes doped with Prussian blue (PB). On a PET substrate, the WE (Carbon conductive ink with the $\mathrm{PB}$ mediator) was printed on one face and the $\mathrm{CE}(\mathrm{Ag} / \mathrm{AgCl})$ on the other. After an electrochemical cleaning, PANI/GOD was added, crosslinked with glutaraldehyde and fixed with PU membrane.

A multiplexed biosensor based on nanostructured conductive hydrogels was prepared by using a multinozzle three-axis inkjet printing system. The printed multiplexed assays can detect glucose, lactate, and triglycerides in real time with good selectivity and high sensitivity, and worked reproducibly in both standard PBS and human serum samples [172]. 3-dimensional stable porous laser-induced graphene on a PI flexible substrate was used as a base for the preparation of glucose and $\mathrm{pH}$ sensor. A PEDOT:PSS layer was first spray-coated to increase the electrode robustness and to deliver uniform electrical conductivity. Furthermore, Pt@Pd nanoparticles and glucose oxidase protected by a permselective membrane were added for the detection of glucose, and PANI was added for the $\mathrm{pH}$ detection [173]. Another method to prepare a multisensor is by weaving the sensing fibers directly into an electrochemical fabric sensor (Figure 7). The sensors prepared by Wang et al. were able to detect a variety of physiological signals such as glucose, $\mathrm{Na}^{+}, \mathrm{K}^{+}, \mathrm{Ca}^{2+}$ and $\mathrm{pH}$ in real time. The active materials were deposited directly on CNT fibers working electrodes. For the glucose sensor, Prussian blue (PB) was used as a mediator; it was electrodeposited and then the glucose oxidase was mixed in a chitosan gel and coated the PB-fiber. PEDOT:PSS was used as an ion-to-electron transducer due to its large impedance change to ion concentration, while polyaniline was used as a $\mathrm{pH}$-sensing fiber, as its surface charges due to protonation resulting in large zeta potential changes [174].

Luo's group [175] prepared a free-standing all polymer electrochemical CEA-biosensor based on a pentaerythritol ethoxylate-PPy (PEE-PPy) composite film. The PEE-PPy film that was prepared electrochemically on a Pt-coated electrode and removed was used as a free-standing working electrode. PPy doped with 2-naphthalene sulfonate was then electropolymerized on the PEE-PPy, creating a sandwich structure [176], then gold nanoparticles were deposed at a- $0.4 \mathrm{~V}$ potential from $\mathrm{HAuCl} / \mathrm{KNO}_{3}$ solution. The AuNPs were 
then modified with carcinoembryonic antigen (CEA), and the PPy composite film-based electrochemical biosensor had a CEA detection limit of $0.033 \mathrm{ng} / \mathrm{mL}$.

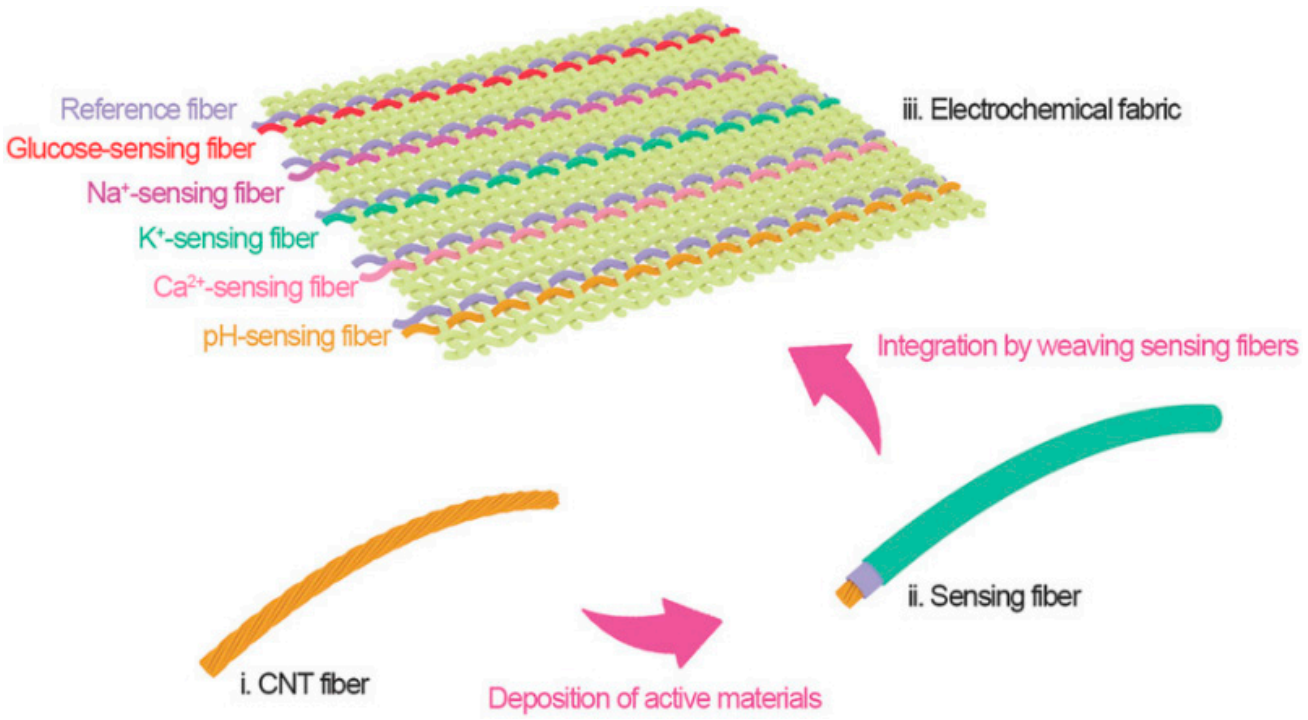

Figure 7. Electrochemical fabric Multisensor. Schematic illustration of weaving sensing fibers, based on active materials deposed on carbon nanotube (CNT) fiber substrates (Reprinted with permission from Ref. [174] Copyright (C 2018 WILEY-VCH Verlag GmbH \& Co. KGaA, Weinheim).

\section{Temperature Sensors}

A transparent, stretchable, gated temperature sensor device that presents high optical transparency stretchability (up to 70\%) was fabricated by Trung et al. [177]. The sensor was prepared as a multilayer in a PDMS sandwich. First, a layer of (PEDOT:PSS)/PU composite elastomeric conductor is used as the source, drain, and gate electrode material, then a layer of PU is added as a dielectric gate, followed by a temperature-responsive channel layer of reduced graphene oxide (rGO) dispersed in PU. Finally, a strain-sensing layer was formed by a composite of silver nanowires AgNWs/PEDOT:PSS/PUD. This sensor showed high sensitivity and was able to detect subtle changes in the strain and temperature of human skin during movement. Sandwich-like PPy-rGO-PPy nano-hybrids were integrated in gelatin hydrogel. Their preparation was based on a universal interface self-assembly reaction in which a spontaneous reduction of graphene oxide and an oxidation polymerization of pyrrole monomers were taking place at $100{ }^{\circ} \mathrm{C}$ under autogenous pressure. The skin-like sensors, with excellent mechanical and electrical behavior, showed high sensibility in the detection of temperature and motion of the human body [178].

By adding an elastomeric crosslinker, glycidoxypropyl trimethoxysilane (GOPS), and a mechanical strengthener, nanofibrillated cellulose (NFC), a PEDOT:PSS hydrogel was reinforced and used as a temperature-pressure dual sensor. To decrease the cross-tear that this type of sensor usually suffers, the transport properties of the conducting aerogels were finely tuned by its exposure to the vapor of high boiling point polar solventsdimethylsulfoxide [179]. To increase the lifetime of an organic temperature sensor that uses PEDOT:PSS as the functional material, Rehman et al. encapsulated it with an atomically thin layer of $\mathrm{Al}_{2} \mathrm{O}_{3}$ through spatial atmospheric atomic layer deposition [180].

A smart bandage, comprising a capacitive touch sensor, a temperature sensor and a drug delivery system was prepared by Honda et al. [181] using large-scale lithography-free processes on a Kapton substrate (Figure 8). The temperature sensor was screen printed from a solution of PEDOT:PSS and CNT paste, and the wireless coil was formed from silver ink, that integrated the capacitive touch sensors, which could detect wirelessly. The sensors, microelectromechanical systems (MEMS) structure, and wireless coil are monolithically integrated onto flexible substrates. The device incorporates touch and temperature sensors 
to monitor health, a drug-delivery system to improve health, and a wireless coil to detect touch. This type of device that not only can detect but can take action by delivering drugs when needed is a promising device for smart medicine. To improve this smart sensor concept, a multiplexed wound monitoring sensor and an electrically controlled drug release were both integrated onto a battery-free, wireless, and flexible platform. The electrode array, based on a flexible PI substrate with serpentine shaped copper interconnections, contained a temperature chip, a uric acid sensor (containing rGo/AuNPs coated with polyvinyl butyral), a pH sensor (containing AuNPs and PANI), and a drug delivery system based on PPY/cefazolin sodium film [182].

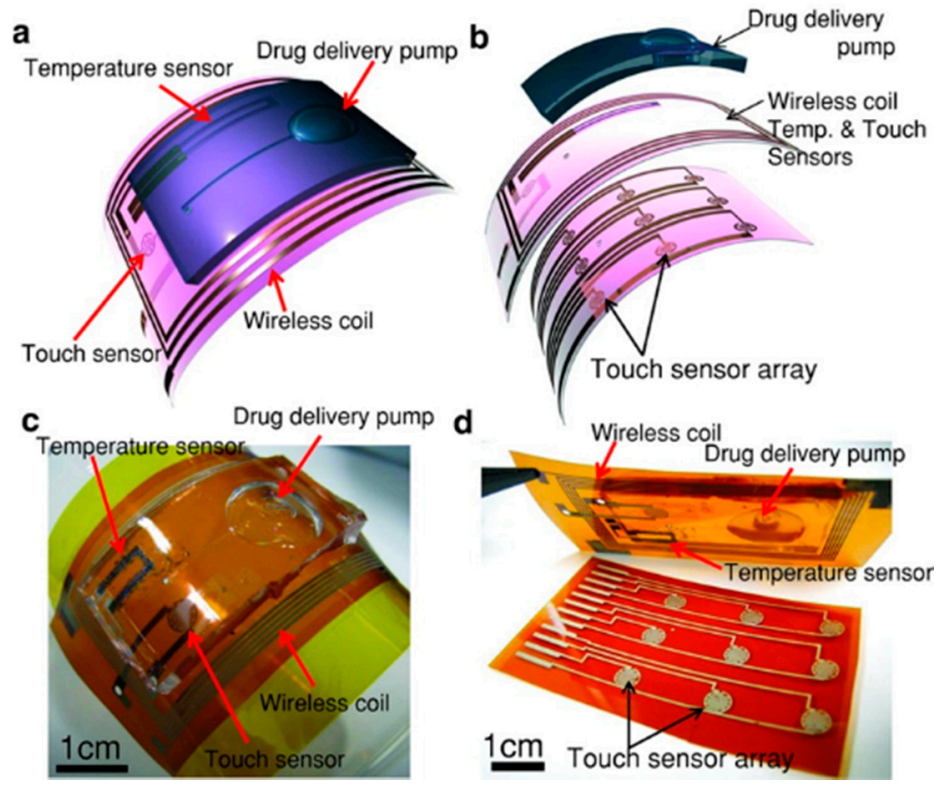

Figure 8. Smart bandage with touch and temperature sensors, a wireless coil, and a drug delivery pump. Schematics with (a) and without (b) a capacitive touch panel. Photos with (c) and without (d) a capacitive touch panel. Reproduced with permission from Ref. [181]. Copyright @ 2014 WILEY-VCH Verlag GmbH \& Co. KGaA, Weinheim.

\section{Humidity}

One of the main problems in wound healing is the moisture content. To address this issue at the wound level without disrupting it, Tessarolo et al. [182] designed a bandage with an integrated moisture sensor. The moisture impedance sensor based on PE-DOT:PSS screen printed a specific geometry onto a commercial bandage, with a directly integrated RFID chip. The sensor showed real time variations over several orders of magnitude between dry and wet states.

An inkjet printable conducting polyaniline was successfully deposited into an interdigitated pattern on a flexible, untreated polymeric substrate and used as a humidity sensor. A direct synthesis of the conducting emeraldine salt phase of the polymer is achieved using sulphonic acids as a dopant via a single-step chemical oxidative polymerization process. At high humidity, the conductivity increases, probably due to a vapor-induced change in the transfer of charge carriers between the polymer chains [183]. Zhao et al. unilaterally deposited PANI on hydrophobic poly(vinylidene fluoride)(PVDF) membrane as a single-sided integrated flexible humidity sensor. The unique micro/nano structure gave the sensor good air permeability, good humidity sensing, fast response, small hysteresis and a stable response, even under bending deformation [184].

\section{Conclusions and Perspectives}

Conductive polymers have been increasingly studied, as they combine the advantages of metals, as good conductors, with the advantages of plastics, such as low price, high 
mechanical flexibility and easy processing. Moreover, they present a better resistance to chemical attacks compared to metals. Ongoing research to improve conductivity, flexibility and transparency is taking place.

The rational design of the flexible sensors plays a tremendous role in their efficiency and applications. Overall, the preferred method for the fabrication of conductive polymers for flexible sensors is the in situ polymerization. Although it is a facile method to incorporate different dopants, as counterions, metal oxides or different types of carbon (from reduced graphene oxide to carbon nanotubes) on an array of substrates, it becomes a challenge in terms of modifying the structure/nanostructure of the film or film composite. Inkjet printing, a rapid, simple, flexible, low cost and high-resolution method, is also a popular fabrication method. The advancement in ink chemistry and printer technology as well as the possibility for mass production makes inkjet printing an attractive method for an array of applications, offering a tunable macrostructure for sensors and biosensors. Electrospinning methods offer the advantage of a tunable nano-structure of the sensor by increasing the active surface area, and the sensitivity of the sensor is also increasing. Although CP are used overall to increase the conductivity of the sensors, the electrochemical method, a simple preparation method with fast response, is rarely used in the development of the flexible electrodes.

Flexible sensors have the advantage of changing their form according to the human body and to the device's applications. To obtain flexibility and wearability, they are mainly designed by incorporating the sensor electrode into a soft substrate. The tunable robustness, low power consumption, real time mapping and analytical performance makes the flexible sensors suitable for an array of applications. These advantages have been used to develop many types of sensors and will certainly continue to make great strides in the years to come for numerous applications. An extensive work was focused on piezoelectric and gas based conductive polymers flexible sensors. Numerous types of flexible sensors, as the ones mentioned in the review, require more attention from the conductive polymers research community. However, some research is still required to make these devices more biocompatible in order to be able to be use them inside the human body, and more biodegradable in order to protect the environment.

Author Contributions: Investigation, I.-A.P., S.L. and B.L.; writing-original draft preparation, I.-A.P., S.L. and B.L.; writing-review and editing, I.-A.P. and B.L. All authors have read and agreed to the published version of the manuscript.

Funding: This research was funded by the European Union through the Fonds Européen de Développement Régional (FEDER), and the Regional Council of Bourgogne Franche-Comte through the PIA-excellence ISITE-BFC program CoMICS: Chemistry of Molecular Interactions Catalysis and Sensors.

Institutional Review Board Statement: Not applicable.

Informed Consent Statement: Not applicable.

Data Availability Statement: No new data were created or analyzed in this study. Data sharing is not applicable to this article.

Conflicts of Interest: The authors declare that they have no conflict of interest.

\section{References}

1. Yan, Y.; Yang, G.; Xu, J.L.; Zhang, M.; Kuo, C.C.; Wang, S.D. Conducting polymer-inorganic nanocomposite-based gas sensors: A review. Sci. Technol. Adv. Mater. 2020, 21, 768-786. [CrossRef] [PubMed]

2. Costa, J.C.; Spina, F.; Lugoda, P.; Garcia-Garcia, L.; Roggen, D.; Münzenrieder, N. Flexible sensors-From materials to applications. Technologies 2019, 7, 35. [CrossRef]

3. Lange, U.; Roznyatovskaya, N.V.; Mirsky, V.M. Conducting polymers in chemical sensors and arrays. Anal. Chim. Acta 2008, 614, 1-26. [CrossRef]

4. Zanardi, C.; Terzi, F.; Seeber, R. Polythiophenes and polythiophene-based composites in amperometric sensing. Anal. Bioanal. Chem. 2013, 405, 509-531. [CrossRef] [PubMed] 
5. Tseghai, G.B.; Mengistie, D.A.; Malengier, B.; Fante, K.A.; van Langenhove, L. PEDOT: PSS-based conductive textiles and their applications. Sensors 2020, 20, 1881. [CrossRef]

6. Arman Kuzubasoglu, B.; Kursun Bahadir, S. Flexible temperature sensors: A review. Sens. Actuators A Phys. 2020, 315,112282 [CrossRef]

7. Tai, H.; Duan, Z.; Wang, Y.; Wang, S.; Jiang, Y. Paper-based sensors for gas, humidity, and strain detections: A review. ACS Appl. Mater. Interfaces 2020, 12, 31037-31053. [CrossRef]

8. Weng, B.; Shepherd, R.L.; Crowley, K.; Killard, A.J.; Wallace, G.G. Printing conducting polymers. Analyst 2010, 135, 2779-2789. [CrossRef]

9. Stempien, Z.; Rybicki, T.; Rybicki, E.; Kozanecki, M.; Szynkowska, M.I. In-situ deposition of polyaniline and polypyrrole electroconductive layers on textile surfaces by the reactive Ink-Jet printing technique. Synth. Met. 2015, 202, 49-62. [CrossRef]

10. Crowley, K.; Smyth, M.R.; Killard, A.J.; Morrin, A. Printing polyaniline for sensor applications. Chem. Pap. 2013, 67, 771-780. [CrossRef]

11. Liu, H.; Zhang, H.; Han, W.; Lin, H.; Li, R.; Zhu, J.; Huang, W. 3D printed flexible strain sensors: From printing to devices and signals. Adv. Mater. 2021, 33, 2004782. [CrossRef] [PubMed]

12. Zhang, J.; Seyedin, S.; Qin, S.; Lynch, P.A.; Wang, Z.; Yang, W.; Wang, X.; Razal, J.M. Fast and scalable wet-spinning of highly conductive PEDOT: PSS fibers enables versatile applications. J. Mater. Chem. A 2019, 7, 6401-6410. [CrossRef]

13. Zhou, J.; Li, E.Q.; Li, R.; Xu, X.; Ventura, I.A.; Moussawi, A.; Anjum, D.H.; Hedhili, M.N.; Smilgies, D.; Lubineau, G.; et al. Semi-metallic, strong and stretchable wet-spun conjugated polymer microfibers. J. Mater. Chem. C 2015, 3, 2528-2538. [CrossRef]

14. Wang, X.X.; Yu, G.F.; Zhang, J.; Yu, M.; Ramakrishna, S.; Long, Y.Z. Conductive polymer ultrafine fibers via electrospinning: Preparation, physical properties and applications. Prog. Mater. Sci. 2021, 115, 100704. [CrossRef]

15. Donoval, M.; Micjan, M.; Novota, M.; Nevrela, J.; Kovacova, S.; Pavuk, M.; Juhasz, P.; Jagelka, M.; Kovac, J.; Jakabovic, J.; et al. Relation between secondary doping and phase separation in PEDOT: PSS films. Appl. Surf. Sci. 2017, 395, 86-91. [CrossRef]

16. Li, P.; Sun, K.; Ouyang, J. Stretchable and conductive polymer films prepared by solution blending. ACS Appl. Mater. Interfaces 2015, 7, 18415-18423. [CrossRef]

17. Rivnay, J.; Inal, S.; Collins, B.A.; Sessolo, M.; Stavrinidou, E.; Strakosas, X.; Tassone, C.; Delongchamp, D.M.; Malliaras, G.G. Structural control of mixed ionic and electronic transport in conducting polymers. Nat. Commun. 2016, 7, 11287. [CrossRef]

18. Dauzon, E.; Lin, Y.; Faber, H.; Yengel, E.; Sallenave, X.; Plesse, C.; Goubard, F.; Amassian, A.; Anthopoulos, T.D. Stretchable and transparent conductive PEDOT: PSS-based electrodes for organic photovoltaics and strain sensors applications. Adv. Funct. Mater. 2020, 30, 2001251. [CrossRef]

19. Vosgueritchian, M.; Lipomi, D.J.; Bao, Z. Highly conductive and transparent PEDOT: PSS films with a fluorosurfactant for stretchable and flexible transparent electrodes. Adv. Funct. Mater. 2012, 22, 421-428. [CrossRef]

20. Gao, Q.; Wang, M.; Kang, X.; Zhu, C.; Ge, M. Continuous Wet-Spinning Of Flexible And Water-Stable Conductive PEDOT: PSS/PVA composite fibers for wearable sensors. Compos. Commun. 2020, 17, 134-140. [CrossRef]

21. Rong, Q.; Lei, W.; Liu, M. Conductive hydrogels as smart materials for flexible electronic devices. Chem.-A Eur. J. 2018, 24, 16930-16943. [CrossRef] [PubMed]

22. Wang, L.; Xu, T.; Zhang, X. Multifunctional conductive hydrogel-based flexible wearable sensors. TrAC-Trends Anal. Chem. 2021, 134, 116130. [CrossRef]

23. Zhao, H.; Su, R.; Teng, L.; Tian, Q.; Han, F.; Li, H.; Cao, Z.; Xie, R.; Li, G.; Liu, X.; et al. Recent advances in flexible and wearable sensors for monitoring chemical molecules. Nanoscale 2022, 14, 1653-1669. [CrossRef] [PubMed]

24. Nag, A.; Mukhopadhyay, S.C.; Kosel, J. Wearable flexible sensors: A review. IEEE Sens. J. 2017, 17, 3949-3960. [CrossRef]

25. Nagamine, K.; Tokito, S. Organic-transistor-based biosensors interfaced with human skin for non-invasive perspiration analysis. Sens. Actuators B Chem. 2021, 349, 130778. [CrossRef]

26. Chung, M.; Fortunato, G.; Radacsi, N. Wearable flexible sweat sensors for healthcare monitoring: A review. J. R. Soc. Interface 2019, 16, 20190217. [CrossRef]

27. Wang, C.; Shirzaei Sani, E.; Gao, W. Wearable bioelectronics for chronic wound management. Adv. Funct. Mater. $2021,2111022$. [CrossRef]

28. Blachowicz, T.; Ehrmann, G.; Ehrmann, A. Textile-based sensors for biosignal detection and monitoring. Sensors 2021, 21, 6042. [CrossRef]

29. Krifa, M. Electrically conductive textile materials-Application in flexible sensors and antennas. Textiles 2021, 1, 239-257. [CrossRef]

30. Gualandi, I.; Tessarolo, M.; Mariani, F.; Possanzini, L.; Scavetta, E.; Fraboni, B. Textile chemical sensors based on conductive polymers for the analysis of sweat. Polymers 2021, 13, 894. [CrossRef]

31. Wang, L.; Fu, X.; He, J.; Shi, X.; Chen, T.; Chen, P.; Wang, B.; Peng, H. Application challenges in fiber and textile electronics. Adv. Mater. 2020, 32, 1901971. [CrossRef]

32. Feron, K.; Lim, R.; Sherwood, C.; Keynes, A.; Brichta, A.; Dastoor, P.C. Organic bioelectronics: Materials and biocompatibility. Int. J. Mol. Sci. 2018, 19, 2382. [CrossRef] [PubMed]

33. Lee, S.; Ozlu, B.; Eom, T.; Martin, D.C.; Shim, B.S. Electrically conducting polymers for bio-interfacing electronics: From neural and cardiac interfaces to bone and artificial tissue biomaterials. Biosens. Bioelectron. 2020, 170, 112620. [CrossRef] [PubMed] 
34. Possanzini, L.; Tessarolo, M.; Mazzocchetti, L.; Campari, E.G.; Fraboni, B. Impact of fabric properties on textile pressure sensors performance. Sensors 2019, 19, 4686. [CrossRef] [PubMed]

35. Pani, D.; Achilli, A.; Bonfiglio, A. Survey on textile electrode technologies for electrocardiographic (ECG) monitoring, from metal wires to polymers. Adv. Mater. Technol. 2018, 3, 1800008. [CrossRef]

36. Pani, D.; Achilli, A.; Spanu, A.; Bonfiglio, A.; Gazzoni, M.; Botter, A. Validation of polymer-based screen-printed textile electrodes for surface EMG detection. IEEE Trans. Neural Syst. Rehabil. Eng. 2019, 27, 1370-1377. [CrossRef] [PubMed]

37. Tai, H.; Wang, S.; Duan, Z.; Jiang, Y. Evolution of breath analysis based on humidity and gas sensors: Potential and challenges Sens. Actuators B Chem. 2020, 318, 128104. [CrossRef]

38. le Maout, P.; Wojkiewicz, J.L.; Redon, N.; Lahuec, C.; Seguin, F.; Dupont, L.; Mikhaylov, S.; Noskov, Y.; Ogurtsov, N.; Pud, A. Polyaniline nanocomposites based sensor array for breath ammonia analysis. Portable e-Nose approach to non-invasive diagnosis of chronic kidney disease. Sens. Actuators B Chem. 2018, 274, 616-626. [CrossRef]

39. Mattana, G.; Kinkeldei, T.; Leuenberger, D.; Ataman, C.; Ruan, J.J.; Molina-Lopez, F.; Quintero, A.V.; Nisato, G.; Tröster, G.; Briand, D.; et al. Woven temperature and humidity sensors on flexible plastic substrates for E-textile applications. IEEE Sens. J. 2013, 13, 3901-3909. [CrossRef]

40. Ibanez, J.G.; Rincón, M.E.; Gutierrez-Granados, S.; Chahma, M.; Jaramillo-Quintero, O.A.; Frontana-Uribe, B.A. Conducting polymers in the fields of energy, environmental remediation, and chemical-chiral sensors. Chem. Rev. 2018, 118, 4731-4816. [CrossRef]

41. Wong, Y.C.; Ang, B.C.; Haseeb, A.S.M.A.; Baharuddin, A.A.; Wong, Y.H. Review-Conducting polymers as chemiresistive gas sensing materials: A review. J. Electrochem. Soc. 2020, 167, 037503. [CrossRef]

42. Alrammouz, R.; Podlecki, J.; Abboud, P.; Sorli, B.; Habchi, R. A review on flexible gas sensors: From materials to devices. Sens. Actuators A Phys. 2018, 284, 209-231. [CrossRef]

43. Shakeel, A.; Rizwan, K.; Farooq, U.; Iqbal, S.; Altaf, A.A. Advanced polymeric/inorganic nanohybrids: An integrated platform for gas sensing applications. Chemosphere 2022, 294, 133772. [CrossRef] [PubMed]

44. Tomić, M.; Šetka, M.; Vojkůvka, L.; Vallejos, S. Vocs sensing by metal oxides, conductive polymers, and carbon-based materials. Nanomaterials 2021, 11, 552. [CrossRef]

45. Nazmul Islam, G.M.; Collie, S.; Qasim, M.; Azam Ali, M. Highly stretchable and flexible melt spun thermoplastic conductive yarns for smart textiles. Nanomaterials 2020, 10, 2324. [CrossRef] [PubMed]

46. Zhang, H.; Wang, M.Y. Multi-axis soft sensors based on dielectric elastomer. Soft Robot. 2016, 3, 3-12. [CrossRef]

47. Chen, J.; Yu, Q.; Cui, X.; Dong, M.; Zhang, J.; Wang, C.; Fan, J.; Zhu, Y.; Guo, Z. An overview of stretchable strain sensors from conductive polymer nanocomposites. J. Mater. Chem. C 2019, 7, 11710-11730. [CrossRef]

48. Ouyang, J. Application of intrinsically conducting polymers in flexible electronics. SmartMat 2021, 2, 263-285. [CrossRef]

49. Veeramuthu, L.; Venkatesan, M.; Benas, J.-S.; Cho, C.-J.; Lee, C.-C.; Lieu, F.-K.; Lin, J.-H.; Lee, R.-H.; Kuo, C.-C. Recent progress in conducting polymer composite/nanofiber-based strain and pressure sensors. Polymers 2021, 13, 4281. [CrossRef]

50. Li, Y.; Tatum, W.K.; Onorato, J.W.; Zhang, Y.; Luscombe, C.K. Low elastic modulus and high charge mobility of low-crystallinity indacenodithiophene-based semiconducting polymers for potential applications in stretchable electronics. Macromolecules 2018, 51, 6352-6358. [CrossRef]

51. Brady, S.; Diamond, D.; Lau, K.T. Inherently conducting polymer modified polyurethane smart foam for pressure sensing. Sens. Actuators A Phys. 2005, 119, 398-404. [CrossRef]

52. Tjahyono, A.P.; Aw, K.C.; Travas-Sejdic, J. A novel polypyrrole and natural rubber based flexible large strain sensor. Sens. Actuators B Chem. 2012, 166-167, 426-437. [CrossRef]

53. Pan, L.; Chortos, A.; Yu, G.; Wang, Y.; Isaacson, S.; Allen, R.; Shi, Y.; Dauskardt, R.; Bao, Z. An ultra-sensitive resistive pressure sensor based on hollow-sphere microstructure induced elasticity in conducting polymer film. Nat. Commun. 2014, 5, 3002. [CrossRef] [PubMed]

54. Zhong, W.; Liu, Q.; Wu, Y.; Wang, Y.; Qing, X.; Li, M.; Liu, K.; Wang, W.; Wang, D. A nanofiber based artificial electronic skin with high pressure sensitivity and 3D conformability. Nanoscale 2016, 8, 12105-12112. [CrossRef] [PubMed]

55. Shao, Q.; Niu, Z.; Hirtz, M.; Jiang, L.; Liu, Y.; Wang, Z.; Chen, X. High-performance and tailorable pressure sensor based on ultrathin conductive polymer film. Small 2014, 10, 1466-1472. [CrossRef]

56. Chen, J.; Liu, J.; Thundat, T.; Zeng, H. Polypyrrole-doped conductive supramolecular elastomer with stretchability, rapid self-healing, and adhesive property for flexible electronic sensors. ACS Appl. Mater. Interfaces 2019, 11, 18720-18729. [CrossRef]

57. Darabi, M.A.; Khosrozadeh, A.; Mbeleck, R.; Liu, Y.; Chang, Q.; Jiang, J.; Cai, J.; Wang, Q.; Luo, G.; Xing, M. Skin-inspired multifunctional autonomic-intrinsic conductive self-healing hydrogels with pressure sensitivity, stretchability, and 3D printability. Adv. Mater. 2017, 29, 1700533. [CrossRef] [PubMed]

58. Zhang, W.; Wen, J.Y.; Ma, M.G.; Li, M.F.; Peng, F.; Bian, J. Anti-freezing, water-retaining, conductive, and strain-sensitive hemicellulose/polypyrrole composite hydrogels for flexible sensors. J. Mater. Res. Technol. 2021, 14, 555-566. [CrossRef]

59. Gan, D.; Han, L.; Wang, M.; Xing, W.; Xu, T.; Zhang, H.; Wang, K.; Fang, L.; Lu, X. Conductive and tough hydrogels based on biopolymer molecular templates for controlling in situ formation of polypyrrole nanorods. ACS Appl. Mater. Interfaces 2018, 10, 36218-36228. [CrossRef] 
60. Cheng, H.; Wang, B.; Tan, Y.; Yin, Y.; Wang, C. Low-cost, highly sensitive, and flexible piezoresistive pressure sensor characterized by low-temperature interfacial polymerization of polypyrrole on latex sponge. Macromol. Mater. Eng. $2021,306,2000772$. [CrossRef]

61. Li, M.; Li, H.; Zhong, W.; Zhao, Q.; Wang, D. Stretchable conductive polypyrrole/polyurethane (PPy/PU) strain sensor with netlike microcracks for human breath detection. ACS Appl. Mater. Interfaces 2014, 6, 1313-1319. [CrossRef] [PubMed]

62. Niu, H.; Zhou, H.; Wang, H.; Lin, T. Polypyrrole-coated PDMS fibrous membrane: Flexible strain sensor with distinctive resistance responses at different strain ranges. Macromol. Mater. Eng. 2016, 301, 707-713. [CrossRef]

63. Li, Y.; Cheng, X.Y.; Leung, M.Y.; Tsang, J.; Tao, X.M.; Yuen, M.C.W. A flexible strain sensor from polypyrrole-coated fabrics. Synth. Met. 2005, 155, 89-94. [CrossRef]

64. Wang, J.P.; Xue, P.; Tao, X.M. Strain sensing behavior of electrically conductive fibers under large deformation. Mater. Sci. Eng. A 2011, 528, 2863-2869. [CrossRef]

65. Li, T.; Wang, X.; Jiang, S.; Ding, X.; Li, Q. Study on electromechanical property of polypyrrole-coated strain sensors based on polyurethane and its hybrid covered yarns. Sens. Actuators A Phys. 2020, 306, 111958. [CrossRef]

66. Irfan, M.S.; Gill, Y.Q.; Ullah, S.; Naeem, M.T.; Saeed, F.; Hashmi, M. Polyaniline-NBR blends by in situ polymerization: Application as stretchable strain sensors. Smart Mater. Struct. 2019, 28, 095024. [CrossRef]

67. Wang, T.; Zhang, Y.; Liu, Q.; Cheng, W.; Wang, X.; Pan, L.; Xu, B.; Xu, H. A self-healable, highly stretchable, and solution processable conductive polymer composite for ultrasensitive strain and pressure sensing. Adv. Funct. Mater. 2018, $28,1705551$. [CrossRef]

68. Ge, G.; Cai, Y.; Dong, Q.; Zhang, Y.; Shao, J.; Huang, W.; Dong, X. A flexible pressure sensor based on RGO/polyaniline wrapped sponge with tunable sensitivity for human motion detection. Nanoscale 2018, 10, 10033-10040. [CrossRef]

69. Xu, R.; Wang, W.; Sun, J.; Wang, Y.; Wang, C.; Ding, X.; Ma, Z.; Mao, Y.; Yu, D. A flexible, conductive and simple pressure sensor prepared by electroless silver plated polyester fabric. Colloids Surf. A Physicochem. Eng. Asp. 2019, 578, 123554. [CrossRef]

70. Park, H.; Jeong, Y.R.; Yun, J.; Hong, S.Y.; Jin, S.; Lee, S.J.; Zi, G.; Ha, J.S. Stretchable array of highly sensitive pressure sensors consisting of polyaniline nanofibers and Au-coated polydimethylsiloxane micropillars. ACS Nano 2015, 9,9974-9985. [CrossRef]

71. Yu, G.F.; Yan, X.; Yu, M.; Jia, M.Y.; Pan, W.; He, X.X.; Han, W.P.; Zhang, Z.M.; Yu, L.M.; Long, Y.Z. Patterned, highly stretchable and conductive nanofibrous PANI/PVDF strain sensors based on electrospinning and in situ polymerization. Nanoscale 2016, 8 , 2944-2950. [CrossRef] [PubMed]

72. Maity, K.; Garain, S.; Henkel, K.; Schmeißer, D.; Mandal, D. Self-powered human-health monitoring through aligned PVDF nanofibers interfaced skin-interactive piezoelectric sensor. ACS Appl. Polym. Mater. 2020, 2, 862-878. [CrossRef]

73. Jiang, Y.; Chen, Y.; Wang, W.; Yu, D. A Wearable strain sensor based on polyurethane nanofiber membrane with silver nanowires/polyaniline electrically conductive dual-network. Colloids Surf. A Physicochem. Eng. Asp. $2021,629,127477$. [CrossRef]

74. Kayser, L.V.; Lipomi, D.J. Stretchable conductive polymers and composites based on PEDOT and PEDOT: PSS. Adv. Mater. 2019, 31, 1806133. [CrossRef]

75. Losaria, P.M.; Yim, J.H. A highly stretchable large strain sensor based on PEDOT-thermoplastic polyurethane hybrid prepared via in situ vapor phase polymerization. J. Ind. Eng. Chem. 2019, 74, 108-117. [CrossRef]

76. Savagatrup, S.; Chan, E.; Renteria-Garcia, S.M.; Printz, A.D.; Zaretski, A.V.; O’Connor, T.F.; Rodriquez, D.; Valle, E.; Lipomi, D.J. Plasticization of PEDOT: PSS by common additives for mechanically robust organic solar cells and wearable sensors. Adv. Funct. Mater. 2015, 25, 427-436. [CrossRef]

77. Liu, N.; Fang, G.; Wan, J.; Zhou, H.; Long, H.; Zhao, X. Electrospun PEDOT: PSS-PVA nanofiber based ultrahigh-strain sensors with controllable electrical conductivity. J. Mater. Chem. 2011, 21, 18962-18966. [CrossRef]

78. Sun, B.; Long, Y.Z.; Liu, S.L.; Huang, Y.Y.; Ma, J.; Zhang, H.D.; Shen, G.; Xu, S. Fabrication of curled conducting polymer microfibrous arrays via a novel electrospinning method for stretchable strain sensors. Nanoscale 2013, 5, 7041-7045. [CrossRef]

79. Lin, D.-P.; He, H.-W.; Huang, Y.-Y.; Han, W.-P.; Yu, G.-F.; Yan, X.; Long, Y.-Z.; Xia, L.-H. Twisted microropes for stretchable devices based on electrospun conducting polymer fibers doped with ionic liquid. J. Mater. Chem. C 2014, 2, 8962-8966. [CrossRef]

80. Fan, X.; Xu, B.; Wang, N.; Wang, J.; Liu, S.; Wang, H.; Yan, F. Highly conductive stretchable all-plastic electrodes using a novel dipping-embedded transfer method for high-performance wearable sensors and semitransparent organic solar cells. Adv. Electron. Mater. 2017, 3, 1600471. [CrossRef]

81. Kim, H.; Kim, G.; Kim, T.; Lee, S.; Kang, D.; Hwang, M.S.; Chae, Y.; Kang, S.; Lee, H.; Park, H.G.; et al. Transparent, flexible, conformal capacitive pressure sensors with nanoparticles. Small 2018, 14, 1703432. [CrossRef] [PubMed]

82. Choong, C.L.; Shim, M.B.; Lee, B.S.; Jeon, S.; Ko, D.S.; Kang, T.H.; Bae, J.; Lee, S.H.; Byun, K.E.; Im, J.; et al. Highly stretchable resistive pressure sensors using a conductive elastomeric composite on a micropyramid array. Adv. Mater. 2014, 26, 3451-3458. [CrossRef] [PubMed]

83. Han, S.; Liu, C.; Huang, Z.; Zheng, J.; Xu, H.; Chu, S.; Wu, J.; Liu, C. High-performance pressure sensors based on 3D microstructure fabricated by a facile transfer technology. Adv. Mater. Technol. 2019, 4, 1800640. [CrossRef]

84. Fu, H.; Jin, Y.; Ou, H.; Huang, P.; Liu, C.; Luo, Y.; Xiao, Z. High-performance ag nanowires/PEDOT: PSS composite electrodes for PVDF-HFP piezoelectric nanogenerators. J. Mater. Sci. Mater. Electron. 2021, 32, 21178-21187. [CrossRef]

85. Bandodkar, A.J.; Nuñez-Flores, R.; Jia, W.; Wang, J. All-printed stretchable electrochemical devices. Adv. Mater. 2015, 27, 3060-3065. [CrossRef] [PubMed] 
86. Lo, L.W.; Zhao, J.; Wan, H.; Wang, Y.; Chakrabartty, S.; Wang, C. An inkjet-printed PEDOT: PSS-based stretchable conductor for wearable health monitoring device applications. ACS Appl. Mater. Interfaces 2021, 13, 21693-21702. [CrossRef]

87. Rong, Q.; Lei, W.; Chen, L.; Yin, Y.; Zhou, J.; Liu, M. Anti-freezing, conductive self-healing organohydrogels with stable strain-sensitivity at subzero temperatures. Angew. Chem.-Int. Ed. 2017, 56, 14159-14163. [CrossRef]

88. Roh, E.; Hwang, B.U.; Kim, D.; Kim, B.Y.; Lee, N.E. Stretchable, transparent, ultrasensitive, and patchable strain sensor for humanmachine interfaces comprising a nanohybrid of carbon nanotubes and conductive elastomers. ACS Nano 2015, 9, 6252-6261. [CrossRef]

89. Zhao, P.; Zhang, R.; Tong, Y.; Zhao, X.; Zhang, T.; Tang, Q.; Liu, Y. Strain-discriminable pressure/proximity sensing of transparent stretchable electronic skin based on PEDOT: PSS/SWCNT electrodes. ACS Appl. Mater. Interfaces 2020, 12, 55083-55093. [CrossRef]

90. Fan, X.; Wang, N.; Wang, J.; Xu, B.; Yan, F. Highly sensitive, durable and stretchable plastic strain sensors using sandwich structures of PEDOT: PSS and an elastomer. Mater. Chem. Front. 2018, 2, 355-361. [CrossRef]

91. Zhou, J.; Hsieh, Y.L. Conductive polymer protonated nanocellulose aerogels for tunable and linearly responsive strain sensors ACS Appl. Mater. Interfaces 2018, 10, 27902-27910. [CrossRef] [PubMed]

92. Seyedin, S.; Razal, J.M.; Innis, P.C.; Jeiranikhameneh, A.; Beirne, S.; Wallace, G.G. Knitted strain sensor textiles of highly conductive all-polymeric fibers. ACS Appl. Mater. Interfaces 2015, 7, 21150-21158. [CrossRef]

93. Kim, D.; Ahn, S.K.; Yoon, J. Highly stretchable strain sensors comprising double network hydrogels fabricated by microfluidic devices. Adv. Mater. Technol. 2019, 4, 1800739. [CrossRef]

94. Liu, H.; Zhang, S.; Li, Z.; Lu, T.J.; Lin, H.; Zhu, Y.; Ahadian, S.; Emaminejad, S.; Dokmeci, M.R.; Xu, F.; et al. Harnessing the wide-range strain sensitivity of bilayered PEDOT: PSS films for wearable health monitoring. Matter 2021, 4, 2886-2901. [CrossRef] [PubMed]

95. Rohtlaid, K.; Nguyen, G.T.M.; Ebrahimi-Takalloo, S.; Nguyen, T.N.; Madden, J.D.W.; Vidal, F.; Plesse, C. Asymmetric PEDOT: PSS trilayers as actuating and sensing linear artificial muscles. Adv. Mater. Technol. 2021, 6, 2001063. [CrossRef]

96. Zhang, L.; Li, J.; Yue, S.; He, H.; Ouyang, J. Biocompatible blends of an intrinsically conducting polymer as stretchable strain sensors for real-time monitoring of starch-based food processing. Adv. Funct. Mater. 2021, 31, 2102745. [CrossRef]

97. Gao, Q.; Meguro, H.; Okamoto, S.; Kimura, M. Flexible tactile sensor using the reversible deformation of Poly(3-Hexylthiophene) nanofiber assemblies. Langmuir 2012, 28, 17593-17596. [CrossRef]

98. Liu, B.; Liu, X.; Yuan, Z.; Jiang, Y.; Su, Y.; Ma, J.; Tai, H. A flexible $\mathrm{NO}_{2}$ gas sensor based on polypyrrole/nitrogen-doped multiwall carbon nanotube operating at room temperature. Sens. Actuators B Chem. 2019, 295, 86-92. [CrossRef]

99. Bayrakli, I.; Turkmen, A.; Akman, H.; Sezer, M.T.; Kutluhan, S. Applications of external cavity diode laser-based technique to noninvasive clinical diagnosis using expired breath ammonia analysis: Chronic kidney disease, epilepsy. J. Biomed. Opt. 2016, 21, 087004. [CrossRef]

100. DuBois, S.; Eng, S.; Bhattacharya, R.; Rulyak, S.; Hubbard, T.; Putnam, D.; Kearney, D.J. Breath ammonia testing for diagnosis of hepatic encephalopathy. Dig. Dis. Sci. 2005, 50, 1780-1784. [CrossRef]

101. Davies, S.; Spanel, P.; Smith, D. Quantitative analysis of ammonia on the breath of patients in end-stage renal failure. Kidney Int. 1997, 52, 223-228. [CrossRef]

102. Amano, A.; Yoshida, Y.; Oho, T.; Koga, T. Monitoring ammonia to assess halitosis. Oral Surg. Oral Med. Oral Pathol. Oral Radiol. Endod. 2002, 94, 692-696. [CrossRef] [PubMed]

103. Kearney, D.J.; Hubbard, T.; Putnam, D. Breath ammonia measurement in helicobacter pylori infection. Dig. Dis. Sci. 2002, 47, 2523-2530. [CrossRef] [PubMed]

104. Yeole, B.; Sen, T.; Hansora, D.; Mishra, S. Electrical and gas sensing behaviour of polypyrrole/silver sulphide nanocomposites. Am. J. Sens. Technol. 2017, 4, 10-20. [CrossRef]

105. Yang, L.; Yang, L.; Wu, S.; Wei, F.; Hu, Y.; Xu, X.; Zhang, L.; Sun, D. Three-dimensional conductive organic sulfonic acid co-doped bacterial cellulose/polyaniline nanocomposite films for detection of ammonia at room temperature. Sens. Actuators B Chem. 2020, 323, 128689. [CrossRef]

106. Chartuprayoon, N.; Hangarter, C.M.; Rheem, Y.; Jung, H.; Myung, N.V. Wafer-scale fabrication of single polypyrrole nanoribbonbased ammonia sensor. J. Phys. Chem. C 2010, 114, 11103-11108. [CrossRef]

107. Armitage, B.I.; Murugappan, K.; Lefferts, M.J.; Cowsik, A.; Castell, M.R. Conducting polymer percolation gas sensor on a flexible substrate. J. Mater. Chem. C 2020, 8, 12669-12676. [CrossRef]

108. She, C.; Li, G.; Zhang, W.; Xie, G.; Zhang, Y.; Li, L.; Yue, F.; Liu, S.; Jing, C.; Cheng, Y.; et al. A flexible polypyrrole/silk-fiber ammonia sensor assisted by silica nanosphere template. Sens. Actuators A Phys. 2021, 317, 112436. [CrossRef]

109. Wang, W.; Li, Z.; Jiang, T.; Zhao, Z.; Li, Y.; Wang, Z.; Wang, C. Sulfonated poly(ether ether ketone)/polypyrrole core-shell nanofibers: A novel polymeric adsorbent/conducting polymer nanostructures for ultrasensitive gas sensors. ACS Appl. Mater. Interfaces 2012, 4, 6080-6084. [CrossRef]

110. Kumar, L.; Rawal, I.; Kaur, A.; Annapoorni, S. Flexible room temperature ammonia sensor based on polyaniline. Sens. Actuators B Chem. 2017, 240, 408-416. [CrossRef]

111. Bandgar, D.K.; Navale, S.T.; Nalage, S.R.; Mane, R.S.; Stadler, F.J.; Aswal, D.K.; Gupta, S.K.; Patil, V.B. Simple and low-temperature polyaniline-based flexible ammonia sensor: A step towards laboratory synthesis to economical model design. J. Mater. Chem. C 2015, 3, 9461-9468. [CrossRef] 
112. Maity, D.; Kumar, R.T.R. Polyaniline anchored MWCNTs on fabric for high performance wearable ammonia sensor. ACS Sens. 2018, 3, 1822-1830. [CrossRef]

113. Qi, J.; Xu, X.; Liu, X.; Lau, K.T. Fabrication of textile based conductometric polyaniline gas sensor. Sens. Actuators B Chem. 2014, 202, 732-740. [CrossRef]

114. Hong, K.H.; Oh, K.W.; Kang, T.J. Polyaniline-nylon 6 composite fabric for ammonia gas sensor. J. Appl. Polym. Sci. 2004, 92, 37-42. [CrossRef]

115. Guo, Y.; Wang, T.; Chen, F.; Sun, X.; Li, X.; Yu, Z.; Wan, P.; Chen, X. Hierarchical graphene-polyaniline nanocomposite films for high-performance flexible electronic gas sensors. Nanoscale 2016, 8, 12073-12080. [CrossRef] [PubMed]

116. Bandgar, D.K.; Navale, S.T.; Navale, Y.H.; Ingole, S.M.; Stadler, F.J.; Ramgir, N.; Aswal, D.K.; Gupta, S.K.; Mane, R.S.; Patil, V.B. Flexible camphor sulfonic acid-doped PAni $/ \alpha-\mathrm{Fe}_{2} \mathrm{O}_{3}$ nanocomposite films and their room temperature ammonia sensing activity. Mater. Chem. Phys. 2017, 189, 191-197. [CrossRef]

117. Crowley, K.; Morrin, A.; Hernandez, A.; O’Malley, E.; Whitten, P.G.; Wallace, G.G.; Smyth, M.R.; Killard, A.J. Fabrication of an ammonia gas sensor using inkjet-printed polyaniline nanoparticles. Talanta 2008, 77, 710-717. [CrossRef]

118. Bai, S.; Zhao, Y.; Sun, J.; Tian, Y.; Luo, R.; Li, D.; Chen, A. Ultrasensitive room temperature $\mathrm{NH}_{3}$ sensor based on a graphenepolyaniline hybrid loaded on PET thin film. Chem. Commun. 2015, 51, 7524-7527. [CrossRef]

119. Wan, P.; Wen, X.; Sun, C.; Chandran, B.K.; Zhang, H.; Sun, X.M.; Chen, X. Flexible transparent films based on nanocomposite networks of polyaniline and carbon nanotubes for high-performance gas sensing. Small 2015, 11, 5409-5415. [CrossRef]

120. Xue, L.; Wang, W.; Guo, Y.; Liu, G.; Wan, P. Flexible polyaniline/carbon nanotube nanocomposite film-based electronic gas sensors. Sens. Actuators B Chem. 2017, 244, 47-53. [CrossRef]

121. Gavgani, J.N.; Hasani, A.; Nouri, M.; Mahyari, M.; Salehi, A. Highly sensitive and flexible ammonia sensor based on s and n co-doped graphene quantum dots/polyaniline hybrid at room temperature. Sens. Actuators B Chem. 2016, 229, 239-248. [CrossRef]

122. Bandgar, D.K.; Navale, S.T.; Naushad, M.; Mane, R.S.; Stadler, F.J.; Patil, V.B. Ultra-sensitive polyaniline-iron oxide nanocomposite room temperature flexible ammonia sensor. RSC Adv. 2015, 5, 68964-68971. [CrossRef]

123. Zhu, C.; Cakmak, U.; Sheikhnejad, O.; Cheng, X.; Zhang, X.; Xu, Y.; Gao, S.; Zhao, H.; Huo, L.; Major, Z. One step synthesis of $\mathrm{PANI} / \mathrm{Fe}_{2} \mathrm{O}_{3}$ nanocomposites and flexible film for enhanced $\mathrm{NH}_{3}$ sensing performance at room temperature. Nanotechnology 2019, 30, 255502. [CrossRef] [PubMed]

124. Bai, S.; Tian, Y.; Cui, M.; Sun, J.; Tian, Y.; Luo, R.; Chen, A.; Li, D. Polyaniline@SnO 2 heterojunction loading on flexible PET thin film for detection of $\mathrm{NH}_{3}$ at room temperature. Sens. Actuators B Chem. 2016, 226, 540-547. [CrossRef]

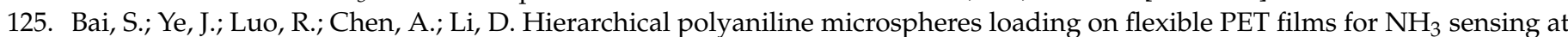
room temperature. RSC Adv. 2016, 6, 6939-6945. [CrossRef]

126. Syrový, T.; Kuberský, P.; Sapurina, I.; Pretl, S.; Bober, P.; Syrová, L.; Hamáček, A.; Stejskal, J. Gravure-printed ammonia sensor based on organic polyaniline colloids. Sens. Actuators B Chem. 2016, 225, 510-516. [CrossRef]

127. Li, S.; Wang, T.; Yang, Z.; He, J.; Wang, J.; Zhao, L.; Lu, H.; Tian, T.; Liu, F.; Sun, P.; et al. Room temperature high performance NH 3 sensor based on GO-rambutan-like polyaniline hollow nanosphere hybrid assembled to flexible PET substrate. Sens. Actuators $B$ Chem. 2018, 273, 726-734. [CrossRef]

128. Jia, X.S.; Tang, C.C.; Yan, X.; Yu, G.F.; Li, J.T.; Zhang, H.D.; Li, J.J.; Gu, C.Z.; Long, Y.Z. Flexible polyaniline/poly (methyl methacrylate) composite fibers via electrospinning and in situ polymerization for ammonia gas sensing and strain sensing. $J$. Nanomater. 2016, 2016, 91028. [CrossRef]

129. Wang, S.; Xie, G.; Tai, H.; Su, Y.; Yang, B.; Zhang, Q.; Du, X.; Jiang, Y. Ultrasensitive flexible self-powered ammonia sensor based on triboelectric nanogenerator at room temperature. Nano Energy 2018, 51, 231-240. [CrossRef]

130. Wang, S.; Liu, B.; Duan, Z.; Zhao, Q.; Zhang, Y.; Xie, G.; Jiang, Y.; Li, S.; Tai, H. PANI nanofibers-supported $\mathrm{Nb}_{2} \mathrm{CT}_{\mathrm{x}}$ nanosheetsenabled selective $\mathrm{NH}_{3}$ detection driven by TENG at room temperature. Sens. Actuators B Chem. 2021, 327, 128923. [CrossRef]

131. Zhang, Y.; Zhang, J.; Jiang, Y.; Duan, Z.; Liu, B.; Zhao, Q.; Wang, S.; Yuan, Z.; Tai, H. Ultrasensitive flexible $\mathrm{NH}_{3}$ gas sensor based on polyaniline $/ \mathrm{SrGe}_{4} \mathrm{O}_{9}$ nanocomposite with Ppt-level detection ability at room temperature. Sens. Actuators B Chem. 2020, 319, 128293. [CrossRef]

132. Pang, Z.; Nie, Q.; Lv, P.; Yu, J.; Huang, F.; Wei, Q. Design of flexible PANI-coated CuO-TiO $2-\mathrm{SiO}_{2}$ heterostructure nanofibers with high ammonia sensing response values. Nanotechnology 2017, 28, 225501. [CrossRef] [PubMed]

133. Pang, Z.; Nie, Q.; Zhu, Y.; Ge, M.; Chen, M. Enhanced ammonia sensing characteristics of $\mathrm{CeO}_{2}$-decorated $\mathrm{SiO}_{2} / \mathrm{PANI}$ freestanding nanofibrous membranes. J. Mater. Sci. 2019, 54, 2333-2342. [CrossRef]

134. Lv, D.; Shen, W.; Chen, W.; Tan, R.; Xu, L.; Song, W. PSS-PANI/PVDF composite based flexible $\mathrm{NH}_{3}$ sensors with Sub-Ppm detection at room temperature. Sens. Actuators B Chem. 2021, 328, 129085. [CrossRef]

135. Xing, X.; Du, L.; Feng, D.; Wang, C.; Tian, Y.; Li, Z.; Liu, H.; Yang, D. Twistable and tailorable $\mathrm{V}_{2} \mathrm{O}_{5} /$ PANI/GO nanocomposites textile for wearable ammonia sensing. Sens. Actuators B Chem. 2022, 351, 130944. [CrossRef]

136. Pang, Z.; Yang, Z.; Chen, Y.; Zhang, J.; Wang, Q.; Huang, F.; Wei, Q. A room temperature ammonia gas sensor based on cellulose $/ \mathrm{TiO}_{2} /$ PANI composite nanofibers. Colloids Surf. A Physicochem. Eng. Asp. 2016, 494, 248-255. [CrossRef]

137. Serafini, M.; Mariani, F.; Gualandi, I.; Decataldo, F.; Possanzini, L.; Tessarolo, M.; Fraboni, B.; Tonelli, D.; Scavetta, E. A wearable electrochemical gas sensor for ammonia detection. Sensors 2021, 21, 7905. [CrossRef] 
138. Kwon, O.S.; Park, E.; Kweon, O.Y.; Park, S.J.; Jang, J. Novel flexible chemical gas sensor based on Poly(3,4-Ethylenedioxythiophene) nanotube membrane. Talanta 2010, 82, 1338-1343. [CrossRef]

139. Wongchoosuk, C.; Jangtawee, P.; Lokavee, S.; Udomrat, S.; Sudkeaw, P.; Kerdcharoen, T. Novel flexible $\mathrm{NH}_{3}$ gas sensor prepared by ink-jet printing technique. Adv. Mater. Res. 2012, 506, 39-42. [CrossRef]

140. Seekaew, Y.; Lokavee, S.; Phokharatkul, D.; Wisitsoraat, A.; Kerdcharoen, T.; Wongchoosuk, C. Low-cost and flexible printed graphene-PEDOT: PSS gas sensor for ammonia detection. Org. Electron. 2014, 15, 2971-2981. [CrossRef]

141. Su, P.G.; Lee, C.T.; Chou, C.Y. Flexible $\mathrm{NH}_{3}$ sensors fabricated by in situ self-assembly of polypyrrole. Talanta 2009, 80, 763-769. [CrossRef] [PubMed]

142. Su, P.G.; Shiu, C.C. Flexible $\mathrm{H}_{2}$ sensor fabricated by layer-by-layer self-assembly of thin films of polypyrrole and modified in situ with Pt nanoparticles. Sens. Actuators B Chem. 2011, 157, 275-281. [CrossRef]

143. Jin, Z.H.; Liu, Y.L.; Chen, J.J.; Cai, S.L.; Xu, J.Q.; Huang, W.H. Conductive polymer-coated carbon nanotubes to construct stretchable and transparent electrochemical sensors. Anal. Chem. 2017, 89, 2032-2038. [CrossRef] [PubMed]

144. Chen, X.; Li, D.; Liang, S.; Li, X.; Zhan, S.; Liu, M. Novel flexible room temperature $\mathrm{NO}_{2}$ gas sensor based on polypyrrole coated $\mathrm{SnO}_{2}$ nanoparticles. In Proceedings of the 8th Annual IEEE International Conference on Nano/Micro Engineered and Molecular Systems, Suzhou, China, 7-10 April 2013; pp. 266-269. [CrossRef]

145. Lin, Y.; Huang, L.; Chen, L.; Zhang, J.; Shen, L.; Chen, Q.; Shi, W. Fully gravure-printed $\mathrm{NO}_{2}$ gas sensor on a polyimide foil using $\mathrm{WO}_{3}$-PEDOT: PSS nanocomposites and Ag electrodes. Sens. Actuators B Chem. 2015, 216, 176-183. [CrossRef]

146. Bahoumina, P.; Hallil, H.; Lachaud, J.L.; Abdelghani, A.; Frigui, K.; Bila, S.; Baillargeat, D.; Ravichandran, A.; Coquet, P.; Paragua, C.; et al. Microwave flexible gas sensor based on polymer multi wall carbon nanotubes sensitive layer. Sens. Actuators $B$ Chem. 2017, 249, 708-714. [CrossRef]

147. Almukhlifi, H.A.; Khasim, S.; Pasha, A. Fabrication and testing of low-cost and flexible smart sensors based on conductive PEDOT-PSS nanocomposite films for the detection of liquefied petroleum gas (LPG) at room temperature. Mater. Chem. Phys. 2021, 263, 124414. [CrossRef]

148. Sun, J.; Shu, X.; Tian, Y.; Tong, Z.; Bai, S.; Luo, R.; Li, D.; Liu, C.C. Facile preparation of polypyrrole-reduced graphene oxide hybrid for enhancing $\mathrm{NH}_{3}$ sensing at room temperature. Sens. Actuators B Chem. 2017, 241, 658-664. [CrossRef]

149. Liu, C.; Tai, H.; Zhang, P.; Yuan, Z.; Du, X.; Xie, G.; Jiang, Y. A high-performance flexible gas sensor based on self-assembled PANI- $\mathrm{CeO}_{2}$ nanocomposite thin film for trace-level $\mathrm{NH}_{3}$ detection at room temperature. Sens. Actuators B Chem. 2018, 261, 587-597. [CrossRef]

150. Gusain, A.; Joshi, N.J.; Varde, P.V.; Aswal, D.K. Flexible NO gas sensor based on conducting polymer poly[N-9'-heptadecanyl-2,7carbazole-alt-5,5-(4',7'-Di-2-thienyl-2', $1^{\prime}, 3^{\prime}$-benzothiadiazole)] (PCDTBT). Sens. Actuators B Chem. 2017, 239, 734-745. [CrossRef]

151. Zhang, D.; Fan, X.; Hao, X.; Dong, G. Facile fabrication of polyaniline nanocapsule modified zinc oxide hexagonal microdiscs for $\mathrm{H}_{2} \mathrm{~S}$ gas sensing applications. Ind. Eng. Chem. Res. 2019, 58, 1906-1913. [CrossRef]

152. Paul, S.; Amalraj, F.; Radhakrishnan, S. CO sensor based on polypyrrole functionalized with iron porphyrin. Synth. Met. 2009, 159, 1019-1023. [CrossRef]

153. Zhang, D.; Wu, Z.; Zong, X. Metal-organic frameworks-derived zinc oxide nanopolyhedra/S, N: Graphene quantum dots/polyaniline ternary nanohybrid for high-performance acetone sensing. Sens. Actuators B Chem. 2019, 288, 232-242. [CrossRef]

154. Hicks, S.M.; Killard, A.J. Electrochemical impedance characterisation of tungsten trioxide-polyaniline nanocomposites for room temperature acetone sensing. Sens. Actuators B Chem. 2014, 194, 283-289. [CrossRef]

155. Sinha, M.; Verma, P.; Panda, S. Metal-phthalocyanine modified doped polyaniline for VOC sensing applications. Flex. Print. Electron. 2020, 5, 014014. [CrossRef]

156. Mabrook, M.F.; Pearson, C.; Petty, M.C. Inkjet-printed polypyrrole thin films for vapour sensing. Sens. Actuators B Chem. 2006, 115, 547-551. [CrossRef]

157. Manjakkal, L.; Dervin, S.; Dahiya, R. Flexible potentiometric PH sensors for wearable systems. RSC Adv. 2020, 10, 8594-8617. [CrossRef]

158. Rahimi, R.; Ochoa, M.; Parupudi, T.; Zhao, X.; Yazdi, I.K.; Dokmeci, M.R.; Tamayol, A.; Khademhosseini, A.; Ziaie, B. A low-cost flexible pH sensor array for wound assessment. Sens. Actuators B Chem. 2016, 229, 609-617. [CrossRef]

159. Rahimi, R.; Ochoa, M.; Tamayol, A.; Khalili, S.; Khademhosseini, A.; Ziaie, B. Highly stretchable potentiometric pH sensor fabricated via laser carbonization and machining of carbon-polyaniline composite. ACS Appl. Mater. Interfaces 2017, 9, 9015-9023. [CrossRef]

160. Park, H.J.; Yoon, J.H.; Lee, K.G.; Choi, B.G. Potentiometric performance of flexible pH sensor based on polyaniline nanofiber arrays. Nano Converg. 2019, 6, 9. [CrossRef]

161. Li, Y.; Mao, Y.; Xiao, C.; Xu, X.; Li, X. Flexible $\mathrm{pH}$ sensor based on a conductive PANI membrane for $\mathrm{pH}$ monitoring. RSC Adv. 2019, 10, 21-28. [CrossRef]

162. Yoon, J.H.; Kim, S.M.; Park, H.J.; Kim, Y.K.; Oh, D.X.; Cho, H.W.; Lee, K.G.; Hwang, S.Y.; Park, J.; Choi, B.G. Highly self-healable and flexible cable-type $\mathrm{pH}$ sensors for real-time monitoring of human fluids. Biosens. Bioelectron. 2020, 150, 111946. [CrossRef] [PubMed] 
163. Zhai, Q.; Yap, L.W.; Wang, R.; Gong, S.; Guo, Z.; Liu, Y.; Lyu, Q.; Wang, J.; Simon, G.P.; Cheng, W. Vertically aligned gold nanowires as stretchable and wearable epidermal ion-selective electrode for noninvasive multiplexed sweat analysis. Anal. Chem. 2020, 92, 4647-4655. [CrossRef]

164. Reid, D.O.; Smith, R.E.; Garcia-Torres, J.; Watts, J.F.; Crean, C. Solvent treatment of wet-spun PEDOT: PSS fibers for fiber-based wearable $\mathrm{pH}$ sensing. Sensors 2019, 19, 4213. [CrossRef] [PubMed]

165. Kim, Y.; Lim, T.; Kim, C.H.; Yeo, C.S.; Seo, K.; Kim, S.M.; Kim, J.; Park, S.Y.; Ju, S.; Yoon, M.H. Organic electrochemical transistor-based channel dimension-independent single-strand wearable sweat sensors. NPG Asia Mater. 2018, 10, 1086-1095. [CrossRef]

166. Mariani, F.; Gualandi, I.; Tessarolo, M.; Fraboni, B.; Scavetta, E. PEDOT: Dye-based, flexible organic electrochemical transistor for highly sensitive $\mathrm{pH}$ monitoring. ACS Appl. Mater. Interfaces 2018, 10, 22474-22484. [CrossRef]

167. Mariani, F.; Gualandi, I.; Tonelli, D.; Decataldo, F.; Possanzini, L.; Fraboni, B.; Scavetta, E. Design of an electrochemically gated organic semiconductor for $\mathrm{pH}$ sensing. Electrochem. Commun. 2020, 116, 106763. [CrossRef]

168. Bhattacharyya, D.; Senecal, K.; Marek, P.; Senecal, A.; Gleason, K.K. High surface area flexible chemiresistive biosensor by oxidative chemical vapor deposition. Adv. Funct. Mater. 2011, 21, 4328-4337. [CrossRef]

169. Wang, Y.; Qing, X.; Zhou, Q.; Zhang, Y.; Liu, Q.; Liu, K.; Wang, W.; Li, M.; Lu, Z.; Chen, Y.; et al. The woven fiber organic electrochemical transistors based on polypyrrole nanowires/reduced graphene oxide composites for glucose sensing. Biosens. Bioelectron. 2017, 95, 138-145. [CrossRef]

170. Li, J.; Rossignol, F.; Macdonald, J. Inkjet printing for biosensor fabrication: Combining chemistry and technology for advanced manufacturing. Lab A Chip 2015, 15, 2538-2558. [CrossRef]

171. Cai, Y.; Liang, B.; Chen, S.; Zhu, Q.; Tu, T.; Wu, K.; Cao, Q.; Fang, L.; Liang, X.; Ye, X. One-step modification of nanopolyaniline/glucose oxidase on double-side printed flexible electrode for continuous glucose monitoring: Characterization, cytotoxicity evaluation and in vivo experiment. Biosens. Bioelectron. 2020, 165, 112408. [CrossRef]

172. Li, L.; Pan, L.; Ma, Z.; Yan, K.; Cheng, W.; Shi, Y.; Yu, G. All inkjet-printed amperometric multiplexed biosensors based on nanostructured conductive hydrogel electrodes. Nano Lett. 2018, 18, 3322-3327. [CrossRef]

173. Zahed, M.A.; Barman, S.C.; Das, P.S.; Sharifuzzaman, M.; Yoon, H.S.; Yoon, S.H.; Park, J.Y. Highly Flexible and conductive poly(3,4ethylene dioxythiophene)-poly (styrene sulfonate) anchored 3-dimensional porous graphene network-based electrochemical biosensor for glucose and $\mathrm{pH}$ detection in human perspiration. Biosens. Bioelectron. 2020, 160, 112220. [CrossRef] [PubMed]

174. Wang, L.; Wang, L.; Zhang, Y.; Pan, J.; Li, S.; Sun, X.; Zhang, B.; Peng, H. Weaving sensing fibers into electrochemical fabric for real-time health monitoring. Adv. Funct. Mater. 2018, 28, 1804456. [CrossRef]

175. Song, J.; Teng, H.; Xu, Z.; Liu, N.; Xu, L.; Liu, L.; Gao, F.; Luo, X. Free-standing electrochemical biosensor for carcinoembryonic antigen detection based on highly stable and flexible conducting polypyrrole nanocomposite. Microchem. Acta 2021, 188, 217. [CrossRef] [PubMed]

176. Gao, F.; Song, J.; Xu, Z.; Xu, L.; Guo, Y.; Miao, L.; Luo, X. All-polymer free-standing electrodes for flexible electrochemical sensors. Sens. Actuators B Chem. 2021, 334, 129675. [CrossRef]

177. Trung, T.Q.; Ramasundaram, S.; Hwang, B.U.; Lee, N.E. An all-elastomeric transparent and stretchable temperature sensor for body-attachable wearable electronics. Adv. Mater. 2016, 28, 502-509. [CrossRef] [PubMed]

178. Yang, X.; Cao, L.; Wang, J.; Chen, L. Sandwich-like polypyrrole/reduced graphene oxide nanosheets integrated gelatin hydrogel as mechanically and thermally sensitive skinlike bioelectronics. ACS Sustain. Chem. Eng. 2020, 8, 10726-10739. [CrossRef]

179. Han, S.; Jiao, F.; Khan, Z.U.; Edberg, J.; Fabiano, S.; Crispin, X. Thermoelectric polymer aerogels for pressure-temperature sensing applications. Adv. Funct. Mater. 2017, 27, 1703549. [CrossRef]

180. Mutee ur Rehman, M.; Muqeet Rehman, M.; Sajid, M.; Lee, J.W.; Na, K.H.; Ko, J.B.; Choi, K.H. Significance of encapsulating organic temperature sensors through spatial atmospheric atomic layer deposition for protection against humidity. J. Mater. Sci. Mater. Electron. 2018, 29, 14396-14405. [CrossRef]

181. Honda, W.; Harada, S.; Arie, T.; Akita, S.; Takei, K. Wearable, human-interactive, health-monitoring, wireless devices fabricated by macroscale printing techniques. Adv. Funct. Mater. 2014, 24, 3299-3304. [CrossRef]

182. Xu, G.; Lu, Y.; Cheng, C.; Li, X.; Xu, J.; Liu, Z.; Liu, J.; Liu, G.; Shi, Z.; Chen, Z.; et al. Battery-free and wireless smart wound dressing for wound infection monitoring and electrically controlled on-demand drug delivery. Adv. Funct. Mater. 2021, 31, 2100852. [CrossRef]

183. Kulkarni, M.V.; Apte, S.K.; Naik, S.D.; Ambekar, J.D.; Kale, B.B. Ink-Jet printed conducting polyaniline based flexible humidity sensor. Sens. Actuators B Chem. 2013, 178, 140-143. [CrossRef]

184. Zhao, H.; Wang, Z.; Li, Y.; Yang, M. Single-sided and integrated polyaniline/poly(vinylidene fluoride) flexible membrane with micro/nanostructures as breathable, nontoxic and fast response wearable humidity sensor. J. Colloid Interface Sci. 2022, 607, 367-377. [CrossRef] [PubMed] 